\title{
Measuring engagement in antisocial behavior during late adolescence and early adulthood for typically developing youth
}

James M. Ogilvie ${ }^{1 \dagger}$, Anna Stewart ${ }^{1,2}$ and David H.K. Shum ${ }^{3,4}$

\author{
${ }^{1}$ Griffith Criminology Institute, Griffith University \\ ${ }^{2}$ School of Criminology and Criminal Justice, Griffith University \\ ${ }^{3}$ Department of Rehabilitation Sciences, Hong Kong Polytechnic University \\ ${ }^{4}$ School of Applied Psychology, Griffith University
}

${ }^{\dagger}$ Corresponding author

j.ogilvie@griffith.edu.au

ORCID: 0000-0003-2294-5665

176 Messines Ridge Road

Griffith Criminology Institute, Griffith University

Mount Gravatt, QLD 4122 AUSTRALIA

Conflict of interest: The authors declare that they have no conflicts of interest.

Citation: Ogilvie, J. M., Stewart, A., \& Shum, D. H. K. (2020). Measuring Engagement in Antisocial Behavior During Late Adolescence and Early Adulthood for Typically Developing Youth. Child Psychiatry \& Human Development. doi:10.1007/s10578-020-01005-5 
Measuring engagement in antisocial behavior during late adolescence and early adulthood for typically developing youth

\begin{abstract}
Research examining the nature and extent of participation in antisocial behavior (ASB) in typically developing individuals during late adolescence and early adulthood remains rare. A self-report instrument for measuring participation in ASB was developed and administered to an Australian sample of 404 youth (64.9\% females) aged 17 to 22-years using item-response theory methods. All participants reported involvement in multiple forms of ASB, although this involvement was skewed toward less serious behaviors, suggesting that engagement in these behaviors were common for typically developing youth. Unlike previous research, few sex differences were detected, with females' self-reported involvement in ASB similar to that of males. A need for ongoing longitudinal research in typically developing samples was highlighted, particularly on the transition to adulthood.
\end{abstract}

Keywords: self-report; antisocial behavior; adolescence; item-response theory. 
Antisocial behavior (ASB) refers to a wide variety of actions and attitudes that have the common feature of violating societal norms and the personal or property rights of others (Burt 2009; American Psychiatric Association 2013). Examples of ASB during adolescence range from minor or relatively normative behaviors, including lying, underage alcohol and cigarette use and occasional truancy from school, to more serious behaviors, including assault, sexual aggression, theft and animal cruelty. A striking and well-established feature of the developmental period of adolescence is an increased rate of participation in most forms of antisocial and criminal activity that then declines as individuals enter adulthood, which is often referred to as the age-crime curve (DeLisi and Piquero 2011). The aggregate spike of engagement in ASB during adolescence has strengthened the view that ASB participation is normative and transient during this period (Moffitt 2018). However, research of "normative" participation in ASB during adolescence among typically developing individuals remains rare. This has made it difficult to define what such behavior constitutes, as well as understand the factors that drive the developmental trend. The aim of this study was to address the gap in knowledge regarding the nature and extent of ASB engagement among typically developing youth through the development and administration of a self-report instrument designed to measure ASB as a multifaceted construct. To provide a context for the current study, research relating to the links between age and crime, and the measurement of ASB through self-report methods will be summarized.

Age and crime

The age-crime relationship has been consistently replicated across longitudinal and prospective samples and cohorts using both official and self-reported data sets, in the United Kingdom (Piquero et al. 2007), United States (Loeber et al. 2012), New Zealand (Moffitt et al. 2002), Finland (Elonheimo et al. 2014), Netherlands (Blokland and Nieuwbeerta 2005), Denmark (Brennan et al. 2000) and Australia (Bor et al. 2004). Findings from these studies indicate that a significant proportion of a population experience contact with the justice system by early adulthood but do not persist in offending. For example, in a study examining rates of offending in an Australian birth cohort, it was estimated that $37.7 \%$ of the cohort had experienced a formal police caution or guilty juvenile or adult court appearance by the age of 22/23 years old, with males (59.3\%) being more likely than females $(21.3 \%)$ to experience this contact (Stewart et al. 2007). Furthermore, the majority of these young people (60\%) only had one contact with the justice system. This is consistent with Australian crime statistics indicating that offenders aged 15-19 years are more likely than any other age group to be processed by police for the commission of an offence and only have one contact with police (Australian 
Institute of Criminology 2014). Further, international self-report data generally confirms that a significant proportion of youth engage in delinquent or ASB during adolescence (Enzmann et al. 2010).

Closer examination of the age-crime curve highlights that offending is not evenly distributed throughout a population, but rather concentrated in a small minority of individuals, variously referred to as serious, chronic, severe or career criminals (Moffitt 2006b; Jolliffe et al. 2017; Blumstein et al. 1986). For example, Elonheimo et al. (2014) found that for males, over half of crimes were committed by $3 \%$ of males. Such findings highlight the importance of unpacking the aggregate age-crime curve, and this has been the focus of a vast amount of research (DeLisi and Piquero 2011). In this regard, research efforts have been dominated by efforts to identify and examine the characteristics of the small group of chronic offenders accounting for a large proportion of offending. This focus is justifiable, given the level and impact of offending committed by these individuals. However, this has limited understanding of the larger proportion of individuals whose offending is potentially limited to and largely concentrated within adolescence and early adulthood.

Specific examination of so-called "normative" participation in ASB during adolescence remains rare, although there have been some attempts to explore broad trends in the nature and type of offending that primarily occurs during adolescence. For example, adolescents are more likely than adults to engage in illegal activities in the presence of co-offenders (Stolzenberg and D'Alessio 2008; Warr 2002). This suggests that ASB during adolescence is significantly shaped by peer and social influences. Further, at an aggregate population level and using the coarse behavioural distinction between aggressive and non-aggressive rule breaking behaviours, the most frequent forms of ASB during adolescence are non-aggressive rule breaking (Burt 2012; Tremblay 2010). Additionally, there is evidence indicating that a significant proportion of adolescent delinquency occurs in the context of alcohol and substance use (Gatti et al. 2013). However, more detailed examinations of the types of ASB and offending that occur during adolescence are needed, including how such offending may differ compared to other developmental periods. For example, research is required to examine whether the offending behavior for individuals whose ASB is limited to the adolescent/early adult period differs compared to the offending behavior of individuals whose ASB persists from childhood and into adulthood.

In examining the age-crime curve, different patterns in offending across age emerge when disaggregating according to sex. It is consistently noted that the prevalence of offending is much higher for males compared to females across all types of offending (DeLisi and Piquero 2011). There is some evidence to suggest that males are almost entirely responsible for the rise in offending that occurs throughout adolescence, with the prevalence of female offending remaining consistently low across age (Elonheimo et al. 2014; 
Pulkkinen et al. 2009). Indeed, offending is typically more prevalent than non-offending for males during adolescence (e.g., Elonheimo et al. 2014), highlighting the normative nature of the behavior. However, it is not known whether the pattern of greater male participation in offending also applies to more normative forms of ASB that occur during adolescence.

\section{Antisocial behavior and the self-report approach}

It is possible that much of the ASB and offending by typically developing adolescents and young adults goes undetected by authorities, with official records underestimating engagement and being inadequate to examine these behaviors. The self-report method is an important approach to examine ASB and offending that does not come to the attention of the justice system and has been used extensively in measuring the prevalence of ASB (Junger-Tas and Marshall 1999). However, many self-report studies draw samples from "at risk" or known antisocial groups, and therefore may not be representative of typically developing youth. In revising the Australian Self-report Delinquency Scale, Curcio et al. (2015) provided some insight into the ASB of a sample of typically developing school-aged adolescents aged 13 to 17-years. Results indicated that rates of participation varied across types of ASB as a function of seriousness, with lower prevalence of engagement for more serious behaviors and vice-versa. Further, there were few sex differences in self-reported engagement in ASB, although where differences did exist, it was generally males reporting higher levels of ASB participation (e.g., getting into fights, possessing a weapon at school). These results highlight the importance of considering ASB as multifaced.

ASB is a complex and multifactorial construct that cannot be clearly conceptualized under a single theoretical framework (Rutter 2003). Current research strongly suggests there are distinct subgroups of individuals who engage in ASB with different underlying etiologies (Burt 2009). The concept of ASB as a multifactorial construct guided the development of the self-report tool in this study. While a large number of self-report instruments for the assessment of involvement in ASB exist, it is argued that the need for a new instrument was justified by two reasons. First, existing instruments typically do not partition ASB into distinct categories, and hence treat antisocial or delinquent behavior as a unitary construct. This complicates efforts to examine the factors underpinning the development and expression of ASB, where different forms of ASB may be underpinned by different explanatory factors. Second, existing instruments do not reflect emerging trends in ASB adolescents engage in (e.g., online forms of ASB). 
The most common technique used to combine self-report information across multi-item measures of ASB is summative scaling, where the sum or mean of a set of items represents an individual's score on a measure. However, summative scaling may not be the best method for combining information on measures of ASB for a number of reasons. Summative scaling gives greatest weight to the least serious (and presumably least important) offences in a measure. This is due to the limited and skewed distributions of self-reports of offending, with the modal response to items being zero, and a substantial proportion of participants being at the absolute floor of a summed scale (Osgood et al. 2002). Items representing less serious forms of ASB are more likely to be endorsed, while few participants will endorse involvement in serious forms of ASB. In addition, factor-analytic approaches to structuring and combining information across multi-item measures also have difficulties when applied to non-normally distributed data on engagement in ASB. Piquero et al. (2002) highlight that factor-analytic approaches fail to account for: a) variation in latent trait distances between ordinal response categories; b) variation in the weight (i.e., seriousness) of particular items; and c) variation in the extent to which items and individuals exhibit significant misfit to an overall measure.

Item-response theory (IRT) is a statistical framework for combining scores on multi-item measures of ASB that addresses some of the problems with summative scaling methods (Osgood et al. 2002). IRT is a general framework for estimating the functional relationship between an underlying latent trait for an individual (i.e., ASB) and their responses on a set of item-level stimuli (i.e., a self-report survey). The latent trait is assumed to underlie, or drive observed item responses by individuals (for more detailed descriptions of IRT methods, see: Osgood et al. 2002; Raudenbush et al. 2003).

\section{Research Questions and Hypotheses}

To address the gap in knowledge regarding the nature and extent of engagement in ASB among typically developing youth, two research questions were addressed: 1) What is the frequency of participation in different forms of ASB for a typically developing sample of youth; and 2) Are there age-related changes in participation of different forms of ASB from late adolescence to early adulthood? A self-report instrument was developed to assess adolescent involvement in a wide range of ASB, varying along a continuum of seriousness that could be partitioned into subcategories. The intent was to create an instrument capable of measuring ASB as a multifaceted construct involving distinct types of antisocial behavior for youth both involved and not involved with the justice system. Based on findings from other self-report studies of ASB (Osgood et al. 2002; Piquero et al. 2002; Raudenbush et al. 2003; Curcio et al. 2015), it was hypothesized that self-reported involvement in 
ASB would be non-normally distributed throughout the sample and highly skewed, with the majority of individuals reporting low levels of involvement in most antisocial acts, with this being more pronounced for more serious forms of ASB. In relation to age-related changes in ASB during late adolescence, no specific hypotheses were posed, given that there is limited research examining age-related changes in specific subtypes of ASB during late adolescence for typically developing individuals. Finally, in relation to sex differences, it was hypothesized that males would engage in more ASB across all categories, which is well established in the research literature (Farrington and Ttofi 2014; DeLisi and Piquero 2011).

\section{Method}

\section{Participants}

Participants were undergraduate university students between the ages of 17 and 22 years from a major metropolitan university in Queensland, Australia. They were recruited through a number of methods. First, psychology and criminology students were recruited through course experiment participation pools, with these individuals receiving course-credit for their participation. Second, students in their second and third years of study were approached through in-person advertisements and handing out information sheets during lectures. Third, the opportunity to participate was advertised on university-wide emails to students regarding research participation opportunities, as well as on course-specific online discussion boards. A response rate to the measure could not be calculated, given the varied methods of recruitment used, where the number of potential participants approached could not be determined.

A total of 537 responses were obtained, with 404 included in analyses due to participants either: a) not falling within the study age-range; b) completing the measure more than once; or c) not completing all items on the measure. Participants included 262 females (64.9\%) and 142 males (35.1\%). Participants had a mean age of 19.41 years $(S D=1.51)$. Table 1 provides a summary of additional demographic characteristics of the sample. Of note, $12.4 \%$ of the sample reported a lifetime prevalence of being diagnosed with a mental illness, with females more likely than males to report a mental illness, $\chi^{2}(1, N=404)=5.75, p<.05$. In addition, $9.7 \%$ reported previous official contact with the criminal justice system (i.e., contact with police or courts), with males more likely than females to report such contact, $\chi^{2}(1, N=404)=10.75, p<.001$. Most participants had completed high school-level education (81.9\%), and 77.5\% identified as having a Caucasian Australian ethnicity. 
[INSERT TABLE 1 ABOUT HERE]

\section{Measure development}

The aim was to develop a measure with items that covered a wide range of behaviors ranging in seriousness and were representative of the most common antisocial acts committed by adolescents. A number of approaches were used to generate a list of suitable items. First, items from previously published instruments were considered, including the Australian Self-Reported Delinquency Scale (Carroll et al. 1996), the SelfReported Delinquency Scale (Elliott et al. 1985), the deviant behaviors utilized by Le Blanc and Bouthillier (2003) in their examination of a general deviance construct, and the Youth Risk Behavior Surveillance System (Brener et al. 2013). Second, unstructured interviews were held with a convenience sample of researchers, practitioners and academics in fields related to juvenile offending or working with youth, as well first-year university students. Interviewees were asked to describe common types of antisocial or criminal behaviors engaged in by youth aged from 17 to 22 years old.

From these approaches a list of 86 items was compiled and grouped a-priori according to face content into eight subcategories of antisocial behavior: general rule-breaking or delinquency; aggressive behavior; vehicle-related; illicit substance-related; theft; property-related; technology-related; and sexual-related (see Appendix Table A1). The ASB subcategories were formed after generation of the scale items to reflect relatively mutually independent groups of ASB. It is acknowledged that the items may be grouped according to multiple categories and that there may be some overlap of items across categories.

For each scale item, participants were required to indicate how often they had engaged in that behavior over the past 12-months based on a seven-point ordinal response scale ranging from "Never" to "More than six times". This response was created to obtain an estimate of the 12-month frequency of participation in ASB.

The reading ease score of the scale items was 74.5 , indicating that 4.2 years of schooling is required to comprehend the wording of items (Flesch 1948). Creating easily readable scale items was important, because individuals engaging in persistent ASB commonly exhibit verbal functioning difficulties (Snow and Powell 2012).

\section{Procedure}

The study was conducted in accordance with the Australian National Statement on Ethical Conduct in Research involving Humans (The National Health and Medical Research Council 2015), and ethical approval 
was obtained through the Griffith University Human Research Ethics Committee prior to commencing the study. All potential participants were directed to complete the self-report measures through an online delivery format and after obtaining their informed consent, completed the questionnaire privately in their own time. Participation was voluntary and anonymous, with no identifying information recorded. These approaches were adopted to facilitate open and honest responses to the ASB scale, given the sensitivity of the activities portrayed in the scale. It was not possible to calculate an accurate estimate of the average time taken by participants to complete the questionnaire because participants were able to initiate the questionnaire and return to complete it within a two-week timeframe.

\section{Analytical Strategy}

There were five stages to the analytical strategy leading to the construction of composite scores for different categories of ASB. First, initial item screening was conducted to examine the distribution of responses to each item, as well as the reliability (i.e., internal consistency) of responses collapsed over each ASB category. Second, descriptive analyses using summative scoring methods were conducted to examine the 12-month frequency of self-reported offending separated by ASB category. Third, analyses were conducted to assess the suitability of scale items for IRT analyses (i.e., assessing unidimensionality), which included estimating a series of factor-analytic models for each ASB category. Factor-analytic models were estimated using the fa function in the psych package (Revelle 2017) for R (R Core Team 2017). Fourth, latent scores for each ASB category were constructed using the graded response model (Samejima 1969) approach to IRT. The mirt (Chalmers 2012) package for R (R Core Team 2017) was used to estimate IRT models for the ordinal item responses (i.e., 12month frequency), with a separate model estimated for each category of ASB. Finally, average composite scores for each age and ASB category were estimated from the IRT model to examine possible age-related changes of engagement in ASB during late adolescence.

\section{Results}

\section{Initial Item Screening}

All 86 scale items except two (i.e., "Taken part in a robbery" and "Stolen a car to sell it") received at least one endorsement by a participant. Examination of response distributions indicated that item responses were highly positively skewed, with participants' modally reporting low levels of involvement in most antisocial activities, suggesting a floor effect for most items. There were a smaller number of items that were highly 
negatively skewed with most participants reporting high levels of involvement, suggesting a ceiling effect (i.e., "Sworn at others or called them names", "Been late for work", "Drunk alcohol", "Drunk alcohol in a public place", "Binge drinking", and "Download copyrighted material"). It appears that these ceiling effect items represented less serious forms of ASB. Altogether, there was significant variation across items in relation to response distributions, with this reflecting variation in the seriousness of antisocial activities that each item represented.

Descriptive information for scale items grouped by the eight categories of ASB is provided in Appendix Table A1. McDonald's (1999) omega ( $\omega)$ was used as a congeneric estimate of internal consistency for each ASB category. As documented in Appendix Table A1, $\omega$ estimates ranged from .60 to .88 , indicating that internal consistency was acceptable to good for each ASB category.

\section{Descriptive Summative Analyses}

Participants' item responses were summed within each ASB category as well as overall across all items to produce a total summative score for the scale. Mean frequency density histograms for summed responses for each ASB subcategory and overall were produced (Figure 1) to examine the distribution of summed individual responses. Inspection of these histograms confirmed that for each ASB category, the summed self-report of engagement in these behaviors was positively skewed and left-censored (i.e., individuals generally reporting low levels of engagement in ASB). However, further inspection of the histograms suggested that not all ASB categories were similarly distributed. For example, substance-related ASB appeared more normally distributed than other forms of ASB (but was still significantly positively skewed), suggesting that some of the behaviors captured by the subscale were more common among participants.

\section{[INSERT FIGURE 1 ABOUT HERE]}

Item responses were summed according to the eight ASB subcategories, with descriptive information displayed in Table 2. All mean summed subscale category distributions were significantly positively skewed, and all subscale categories, except sexual, exhibited significant kurtosis. Except for the categories of general rule breaking, substance and total, the modal frequency of self-reported engagement in ASB was zero over the last 12-months. A proportion of individuals reported no engagement in any of the behaviors depicted in the ASB categories over the last 12 -months, although this proportion varied across category. For example, $48.0 \%$ of 
participants reported no engagement in aggressive behaviors over the last 12 months, compared to $75.2 \%$ of participants reporting no engagement in theft behaviors over the past 12 months. Overall, the distribution of responses was typically left censored with the majority of participants reporting low levels of engagement in ASB, highlighting the absence of normality.

[INSERT TABLE 2 ABOUT HERE]

Given the data were not normally distributed, non-parametric Kruskal-Wallis tests $(H)$ were used to examine group differences (i.e., age and sex) in summed ASB category scores. There were significant differences across the levels of age for the substance $(H=11.50, p=.04)$, property $(H=13.20, p=.02)$ and sexual $(H=13.10, p=.02)$ ASB categories. There were significant sex differences in the mean summed scale scores for some ASB categories. Males self-reporting a higher mean of vehicle $(H=5.72, p=.02)$, property $(H$ $=8.02, p=.005)$, and technology $(H=7.08, p=.01)$, ASB over the last 12 months. Females self-reported a higher mean of sexual ASB $(H=4.70, p=.03)$.

Spearman's correlations were calculated to examine the associations among the eight mean summed ASB subcategory 12-month frequency responses (see Table 3). All mean summed ASB categories were significantly positively correlated with each other (all $p<.001$ ), suggesting that they were associated with a general underlying ASB construct.

[INSERT TABLE 3 ABOUT HERE]

\section{Item Response Theory Models}

To facilitate IRT model estimation, the 7-point ordinal scales were collapsed into three ordinal response categories representing: "Never", "1-3 times" and "4 or more times". Using this scheme, six scale items did not have responses to all response categories (i.e., "fired from work or university”, "appeared in court", "broken into premises with intention of stealing", "taken part in robbery", "stolen car to sell it", and "set fire to property") and these items were excluded from further analyses, leaving a total of 82 items. It is possible that the excluded items represented more serious and less common forms of ASB, and therefore less likely to be endorsed. 
Unidimensionality. IRT models are underpinned by an assumption that scale items relate to a unidimensional latent construct (Stout 1990). A series of single-factor solution exploratory factor analyses were conducted for each ASB category using the minimum residual method with no rotation applied to examine unidimensionality. Initial models were estimated for each ASB category to first examine the factor loadings items on a single factor. Single-factor solutions for each category were re-estimated after removing items with factor loadings below .30 (see Appendix Table A2 for these items). However, removing these items resulted in minimal improvements in overall model fit to the data, and also resulted in too few items being available to estimate stable solutions for the technology and sexual ASB categories. Therefore, low-loading items were retained in analyses across all ASB categories.

Appendix Table A2 displays the fit indices for single-factor solution factor analyses for ASB categories. Single factor models accounted for between 21 to $38 \%$ of the variance in item responses across each ASB subcategory. Root mean square error of approximation (RMSEA) values ranged from .00 to .26 , with values above .10 indicating a poor model fit. Comparative fit index (CFI) values ranged from .65 to 1, and Tucker Lewis index (TLI) values ranged from 0.05 to 1 , with values below 90 indicating poor model fit. As mentioned, removal of items with low loadings and re-estimation of models did little to improve single-factor model fit. Overall, model fit indices at best indicated that single-factor solutions for each ASB category only approached adequacy. Single factor model fit appeared poor for the aggression, substance, theft and sexual ASB categories, suggesting that there may have been secondary or multiple latent traits subsumed within these categories.

It may be argued that the eight single-factor solution models for ASB categories were able to demonstrate 'essential unidimensionality'. Essential unidimensionality can be defined as a scale that measures a dominant latent variable with secondary minor latent variables (Stout 1990). Strict adherence to a stringent level of unidimensionality in conducting IRT analyses may not be feasible for real-world data sets, where responses to observed items are often multidimensional. It is argued that IRT methods are robust to minor to moderate violations of local independence (Harwell et al. 1996).

Discrimination Parameters and Item Thresholds. IRT model parameters for scale items were estimated using graded response models (GRM; Samejima 1969) for each ASB category. After estimation of initial GRM models, individual scale items were assessed for goodness of fit using the $S$ - $X^{2}$ item fit index (Orlando and Thissen 2000, 2003; Kang and Chen 2008). The $S-X^{2}$ index could not be calculated for eight items (i.e., "Used a weapon in a fight", "Beat someone up who did nothing to you", "Used other hard drugs", "Stolen 
from bicycle", "Stolen from car or motorbike", "Deliberately damage work property", "Have sex for means", and "Force sex"), due to not enough degrees of freedom being available to calculate the index. There were seven items with significant (i.e., $p<.05) S-X^{2}$ values indicating poor item fit, including: "Talked back impolitely", "Used force to get money or property", "Deliberately hurt an animal", "Sniffed substance on purpose", "Drunk alcohol in unlicensed place", "Binge drinking", and "Stolen $\$ 50$ or more". The 15 items with significant $S-X^{2}$ values or where the index could not be calculated were excluded, resulting in 67 items being available for further analyses.

The GRM models were re-estimated using the remaining 67 items of the ASB scale. Table 4 displays item discrimination parameters, item thresholds and goodness-of-fit statistics for the final GRM models estimated for each ASB category. Discrimination parameters $(\alpha)$ indicate how strongly associated an item is to the latent trait being examined by a scale. Items with high discrimination are better able to distinguish levels of the latent trait, where small differences in the latent trait result in large changes in the probability of endorsing an item.

\section{[INSERT TABLE 4 ABOUT HERE]}

The threshold parameters $\left(\beta_{1}\right.$ and $\left.\beta_{2}\right)$ indicate the level of the latent trait at which the probability of endorsing one choice switches to the next choice. For the current scale, $\beta_{1}$ represents the value of the latent trait at which a respondent will report engaging in the behavior depicted by the item "1-3 times" over the past 12months. Similarly, $\beta_{2}$ represents the value of the latent trait when a respondent will report engaging in the behavior " 4 or more times" over the past 12-months. Higher initial threshold values are likely to represent less common and/or serious forms of ASB, while lower initial threshold values are likely to represent more common and less serious forms of ASB (Osgood et al. 2002). The IRT modelling process appeared to effectively place greater weight on more serious forms of ASB, and less weight on more trivial forms of ASB.

Figure 2 displays the total test information curves for each ASB category, which were calculated by averaging the information curves for the items within each ASB category. These test information curves illustrate the average amount of "psychometric information" (denoted as $I(\theta)$ ) that the items within each ASB category measure across levels of the latent trait (denoted as theta $[\theta]$ ). Theta can be read as a $S D$ unit, with higher values representing a greater magnitude of the underlying latent trait. As the total test information curves indicate in Figure 3, the measure provided most information at about $\theta=+2.0$ across all ASB categories. This 
suggested that the measure was good at distinguishing individuals with moderate to high levels of ASB across the behavior categories but was not good at distinguishing individuals with low levels of ASB.

[INSERT FIGURE 2 ABOUT HERE]

\section{Composite Scores}

Factors scores (a.k.a., ability estimates) were derived from the final GRM model using the expected aposteriori (EAP) for summed scores method (Thissen et al. 1995). Mean ASB category composite factor scores across age and separated by sex are displayed graphically in Figure 3 .

\section{[INSERT FIGURE 3 ABOUT HERE]}

A series of two-way between-subjects ANOVAs were conducted to examine potential sex and age differences in mean composite factor scores for each ASB category that are summarized in Table 5. There were significant main effects of age for general, $F(5,392)=3.09, p=01, \eta_{P}^{2}=.04$, and property, $F(5,392)=3.02, p$ $=.004, \eta_{P}^{2}=.04$ ASB categories. Trend analysis indicated that the main effect of age for general ASB appeared to be best accounted for by decreasing linear trend, $F(1,402)=9.71, p=.002$, suggesting overall self-reported ASB participation decreased with age. The trend analysis for property-related ASB indicated a non-linear cubic trend, $F(3,400)=4.49, p=.004$, suggesting a non-linear change across age (see Figure 4 for illustration).

\section{[INSERT TABLE 5 ABOUT HERE]}

There were significant main effects of sex for the vehicle, $F(1,392)=6.18, p=.01, \eta_{P}^{2}=.02$, property, $F(1,392)=8.03, p=.005, \eta_{P}^{2}=.02$, technology, $F(1,392)=5.57, p=.02, \eta_{P}^{2}=.01$, and sexual, $F(1,392)=$ $6.28, p=.01, \eta_{P}^{2}=.02 \mathrm{ASB}$ categories. Males exhibited higher mean composite scores for the vehicle, property and technology categories, while females exhibited higher mean composite scores on the sexual category. Apart from these sex differences, mean composite scores were largely equivalent across sex.

In summarizing age and sex differences, it was evident that the effect sizes $\left(\eta_{P}^{2}\right)$ were small across all ASB composite scores, including those significant main effects. This suggests that age and sex only accounted 
for a small amount of variance in ASB composite scores, and that other variables may better explain individual variation in ASB for the sample and age-range studied.

\section{Discussion}

This study described the development of a self-report measure of ASB to examine the nature and extent of engagement in ASB among typically developing adolescents during late adolescence. It aimed to address: 1) What is the frequency of participation in different forms of ASB for a typically developing sample of youth; and 2) Are there age-related changes in the frequency of participation in different forms of ASB from late adolescence to early adulthood? We developed a scale that encompassed a wide range of behaviors varying in seriousness that were partitioned into sub-categories of ASB. An IRT methodological approach was adopted to address the limitations of traditional summative scaling methods, given IRT approaches have previously exhibited promise in constructing self-report measures of ASB (Osgood et al. 2002; Raudenbush et al. 2003).

There remain a limited number of studies that have focused on examining samples representative of typically developing youth. Results of this study clearly indicated that engagement in ASB is common for the sample of typically developing youth studied, suggesting such behavior may be relatively normative. All participants reported at least some involvement in ASB and this is consistent with other studies utilizing self-report measures of ASB and deviance in the general population (Piquero et al. 2002). Engagement in ASB appeared to be wide-ranging, with young people self-reporting engagement in a varied range of behaviors (e.g., substance-, property-, and theft-related). This is consistent with existing research highlighting that there are often significant correlations between different forms of ASB (Brindle et al. 2019). For the current study, the mean summed ASB subscale scores were highly correlated, and this suggested that although ASB may be a multidimensional construct, the dimensions of ASB are strongly related to a general underlying ASB construct.

In examining the 12-month summed responses of engagement in ASB, there were some significant cross-sectional differences across age. Mean self-reported engagement in substance- and sexual-related ASB both appeared to increase with age, which possibly reflects increasing maturity and access to opportunities to engage in these behaviors. Consistent with this, alcohol and substance use is known to increase during late adolescence and early adulthood (Australian Institute of Health and Welfare 2014), which is due in part to individuals becoming legally able to access certain substances as well as increased experimentation. In regard to non-significant age-effects for the other ASB categories, it is possible that the age-range of 17 to 22 years 
represents a period of development where participation in ASB is relatively stable. Further research is needed to explore whether the incidence of self-reported participation in ASB changes as individuals progress through adulthood and how these changes may differ across subtypes of ASB.

A major finding of this study was that there were significant variations in participants' responses to items, and this was argued to largely reflect variation in the seriousness of the behaviors each scale item represented. Item-level examination of the ASB scale indicated that participants were more likely to self-report a higher 12-month frequency of engagement in less serious forms of ASB. More serious forms of ASB were less likely to be endorsed by participants. However, all items apart from two (i.e., "Stolen a car to sell it" and "Taken part in a robbery") included in the initial scale were endorsed at least once, including some of the most serious behaviors (e.g., "Beat up someone who did nothing to you", "Force sex"). This suggested that even among a largely typically developing sample of later adolescents, there is a small group of individuals who self-reported involvement in more serious forms of ASB. These findings align with those of Curcio et al. (2015), where participant's responses appeared to vary across items largely as a function of seriousness, with a small number of participants self-reporting engagement in more serious forms of ASB.

From a methodological perspective, and in support of the first hypothesis, the current results were consistent with the findings of other self-report investigations into ASB (Krohn et al. 2010; Piquero et al. 2002). Specifically, participants' responses to the scale items were not normally distributed, being positively skewed through participants modally reporting low levels of involvement in most forms of ASB. These characteristics were carried through traditional summative scoring methods, with summed scale scores for categories of ASB also being highly skewed and not normally distributed.

As a further methodological insight, efforts to check for assumptions of unidimensionality for IRT analyses strongly suggested that ASB was a multidimensional construct that could be separated into meaningfully distinct but related subcategories (i.e., general/rule-breaking, aggressive, vehicle, substance, theft, property, technology and sexual). This was consistent with the findings of (Curcio et al. 2015), who partitioned ASB into eight subscales (i.e., driving/vehicle, alcohol, theft, cheat, disturb, fight, drugs and media) that shared some similarities to the categories constructed for the current study. Comparing the current findings to those of Curcio et al. (2015) highlights that there are multiple approaches to partitioning the construct of ASB that depend heavily on the specific behaviors measured. Theoretical frameworks, such as Moffitt's (2018) developmental taxonomy, may assist in guiding future efforts to partition ASB in a more structured approach. 
Accumulating evidence highlights the importance of considering heterogeneity in ASB when constructing a self-report measure. Factor-analytic studies clearly indicate that there are separable but correlated dimensions within the broader construct of ASB (Burt 2012; Curcio et al. 2015). Some of the ASB categories (i.e., grouped according to face content) utilized for the current study were a poor fit to the data as unidimensional constructs, including the substance, aggression and theft ASB categories. It was likely that this result was due to items tapping into multiple or secondary ASB traits within the broader ASB category and highlighting that further fractionation of the construct may be necessary. For example, items within the aggression category could be further fractionated into reactive vs. instrumental forms of aggression (Burt 2012). As another example, items within the substance category may be further divided into legally regulated (e.g., cigarette and alcohol use) and illegal (e.g., using amphetamines) forms of substance use. Overall, poor model fit suggests that other conceptual categorization schemes might fit the data better (e.g., aggressive-nonaggressive (Burt 2012), destructive-nondestructive and overt-covert (Tremblay 2010) distinctions). Future studies could examine how other categorization schemes may be used to better reflect the underlying multidimensional structure of ASB measured by the scale, and this could be achieved through a data-driven approach (e.g., exploratory factor analysis).

The IRT approach adopted for the current study provided a method of combining information across scale items that accounted for variation in the seriousness of individual items. On face value, the modelling approach appeared to effectively weight more serious forms of ASB. It is important to note that in this context, lower levels of item endorsement effectively equate to higher seriousness, and vice versa. However, this may not always be the case, where an item may be highly endorsed, but represent a serious form of ASB. An example for the current measure was "Driving at high speeds", which was endorsed regularly, and may be argued to be a serious form of ASB, given the behavior has the potential to cause significant harm. This is a methodological issue that needs to be taken into account in constructing self-report measures of ASB.

The IRT analyses indicated that the scale was able to distinguish individuals engaging in moderate to serious levels of ASB but was unable to provide detailed information about the large proportion of individuals engaging in low levels of ASB. This was the case despite an attempt to include less serious forms of ASB in the scale, as suggested by Osgood et al. (2002). Future developments of the scale could include antisocial samples to examine how responses may differ to typically developing youth and determine the sensitivity of the scale in differentiating individuals with higher levels of antisocial latent traits. 
Findings related to sex differences in ASB engagement were not consistent with our hypothesis that males would exhibit a greater propensity to engage in ASB across all subcategories. Examining both traditional summative scale and latent trait (i.e., IRT) results, males on average reported significantly higher frequency of engagement in vehicle, property and technology ASB. In contrast, females reported a significantly higher frequency of engagement in sexual ASB. However, it is important to highlight that these sex differences were small, as evidenced by small effect sizes. Considering these findings, it could be argued that males and females were relatively equivalent their self-reports of engagement in ASB during later adolescence and early adulthood. Female self-reported involvement in ASB largely paralleled the self-reports of males, with no significant differences in mean composite scores for general, aggressive, substance and theft ASB categories. For both summative scale and latent trait, there were no sex differences in the self-reported frequency of involvement in general, vehicle, substance and theft ASB categories. Taking the latent trait and summative scale results together, it appeared that the female propensity to engage in ASB was much closer to the male propensity than expected, and this was consistent with small effect sizes detected for sex differences. This is a novel finding, given that most studies, using both official records and self-report, typically find higher levels of male engagement in ASB. However, there is some evidence to suggest that sex differences in ASB are less pronounced when assessed using self-report measures (Canter 1982).

The finding that males did not always demonstrate a greater propensity to engage in ASB may be due to a number of factors. First, the inclusion of less serious forms of ASB in the self-report measure that females could be more likely to engage in may have reduced any sex differences. Sex differences may only emerge for more serious forms of ASB. Additionally, the lack of consistency in sex differences may be an artefact of the sample studied, whereby sex differences may be less pronounced in a typically developing sample, and/or during the age period studied. Bacon et al. (2014) also found no significant sex difference in self-reported delinquency for a sample of typically developing young adults. Relevant to explaining these results, Moffitt (2006a) highlights that sex differences in ASB are less pronounced for "adolescent limited" offending behavior, but become pronounced for more "life-course persistent" offending. Finally, it was possible that the use of a self-report method was more accurately able to detect ASB committed by females when compared to official records (e.g., arrests, court appearances). In this situation, female ASB may be less likely to come to the attention of authorities, while male ASB is more likely be detected.

Examination of latent trait composite scores indicated that there were age-related differences for some antisocial latent trait categories. Significant non-linear changes across age were observed for general and 
property ASB latent traits, which suggested that there were some age-related changes in the propensity to engage in certain forms of ASB during later adolescence. The failure to find more extensive age-related changes in the propensity to engage in ASB was likely to be a result of the restricted age-range examined. The age range represented in the current study was likely to cover the peak period of engagement in ASB of typically developing youth. Future studies would benefit from examining a wider age range starting from early adolescence and into adulthood to better examine trajectories of engagement in ASB for typically developing individuals. However, examining a wider age range poses measurement challenges in constructing appropriate scale items, given what is considered antisocial can vary as a function of age (e.g., alcohol consumption or engagement in sexual activity at ages 12 versus 24 years old).

Future research is needed to examine the extent to which involvement in ASB for typically developing youth may potentially negatively impact their developmental outcomes, or alternatively, whether these individuals are able to participate in these behaviors without serious and lasting negative outcomes. Ongoing research questions may relate to whether these behaviors are developmentally transient or whether they persist into adulthood, and to what extent. There is some evidence to suggest that ASB that emerges during adolescence can be indicative of more serious externalizing behavior problems for a subset of youth as they enter adulthood (Roisman et al. 2010). Finally, further research with the current measure would be beneficial in comparing selfreported ASB for typically developing youth with a sample of known young offenders, including examination of whether the measure is accurately able to distinguish between these two groups of youth.

Some limitations of the study warrant discussion. The sample was recruited from a single university in an urban/metropolitan region, and this may have restricted the generalizability of results. While this may have resulted in a relatively uniform sample in terms of socioeconomic and educational backgrounds, it was likely to have restricted the external validity of the results. However, students from the recruitment source university are generally characterized as coming from middle-class socioeconomic backgrounds and a cross-section of ethnicities, which was consistent with the current sample demographics. Although the sample has been described as a "typically-developing" group of youth, it is important to consider this within the context of the recruitment source (e.g., attending tertiary education). In addition, it is important to note that age-group comparisons were made in the context of a cross-sectional design, and therefore cannot be considered a developmental analysis. As with all cross-sectional designs, it is possible that systematic differences existed between the age groups that impacted self-report results, therefore making comparisons across age difficult to 
interpret. Only longitudinal data is able to accurately characterize changes associated with maturation and development.

\section{Summary}

In summary, through the development and administration of a self-report measure, it was highlighted that ASB was best represented as a multi-dimensional construct and self-reported engagement in less serious forms of ASB appeared widespread among typically developing adolescents and young adults. Sex differences in self-reported ASB were less pronounced than expected based on historical research, with female participation in ASB largely paralleling male participation. Further longitudinal research is warranted to examine ASB in typically developing samples on the transition from adolescence to adulthood, when aggregate rates of participation in ASB decline.

\section{Compliance with ethical standards}

Funding: JO was awarded an Australian Postgraduate Scholarship to support the completion of this research.

Conflict of Interests: The authors declare that they have no conflict of interest.

Ethical approval: All procedures performed in this study with human participants were in accordance with the ethical standards of the institutional research committee and the Australian National Statement on Ethical Conduct in Human Research (The National Health and Medical Research Council 2015).

Informed Consent: Informed consent was obtained from all individual participants included in the study.

Data Sharing: The data for this research are made available on the Open Science Framework:

https://osf.io/6g8eh/; DOI: 10.17605/OSF.IO/6G8EH. 


\section{References}

American Psychiatric Association (2013). Diagnostic and statistical manual of mental disorders: DSM-5 (5th ed.): American Psychiatric Association.

Australian Institute of Criminology (2014). Australian crime: Facts and figures 2013. In Australian Institute of Criminology (Ed.). Canberra: Australian Institute of Criminology.

Australian Institute of Health and Welfare (2014). National Drug Strategy Household Survey detailed report 2013. Drug Statistics Series No. 28. Cat No. PHE 183. Canberra: Australian Institute of Health and Welfare.

Bacon, A. M., Burak, H., \& Rann, J. (2014). Sex differences in the relationship between sensation seeking, trait emotional intelligence and delinquent behaviour. The Journal of Forensic Psychiatry \& Psychology, 25(6), 673-683, doi:10.1080/14789949.2014.943796.

Blokland, A. A. J., \& Nieuwbeerta, P. (2005). The Effects of Life Circumstances on Longitudinal Trajectories of Offending. Criminology, 43(4), 1203-1240, doi:DOI 10.1111/j.1745-9125.2005.00037.x.

Blumstein, A., Cohen, J., Roth, J., \& Visher, C. A. (1986). Criminal Careers and "Career Criminals" (Vol. 1, Report of the National Academy of Sciences Panel on Criminal Careers). Washington, DC: National Academy Press.

Bor, W., McGee, T. R., \& Fagan, A. A. (2004). Early risk factors for adolescent antisocial behaviour: An Australian longitudinal study. Australian and New Zealand Journal of Psychiatry, 38(5), 365-372, doi:10.1080/j.1440-1614.2004.01365.x.

Brener, N. D., Kann, L., Shanklin, S., Kinchen, S., Easton, D. K., Hawkins, J., et al. (2013). Methodology of the Youth Risk Behavior Surveillance System - 2013. Centers for Disease Control and Prevention Morbidity and Mortality Weekly Report, 62(1), 1-25.

Brennan, P. A., Mednick, S. A., \& Hodgins, S. (2000). Major Mental Disorders and Criminal Violence in a Danish Birth Cohort. Arch Gen Psychiatry, 57(5), 494-500.

Brindle, K. A., Bowles, T. V., \& Freeman, E. (2019). A retrospective examination of antisocial and risk-taking behaviours. Psychiatry, Psychology and Law, 26(4), 644-658, doi:10.1080/13218719.2019.1618747.

Burt, S. A. (2009). Are there meaningful etiological differences within antisocial behavior? Results of a metaanalysis. Clinical Psychology Review, 29(2), 163-178, doi:10.1016/j.cpr.2008.12.004.

Burt, S. A. (2012). How do we optimally conceptualize the heterogeneity within antisocial behavior? An argument for aggressive versus non-aggressive behavioral dimensions. Clinical Psychology Review, 32(4), 263-279, doi:10.1016/j.cpr.2012.02.006.

Canter, R. J. (1982). Sex differences in self-report delinquency. Criminology, 20(3-4), 373-394.

Carroll, A., Durkin, K., Houghton, S., \& Hattie, J. (1996). An adaptation of Mak's self-reported delinquency scale for Western Australian adolescents. Australian Journal of Psychology, 48(1), 1-7, doi: $10.1080 / 00049539608259498$.

Chalmers, R. P. (2012). mirt: A Multidimensional Item Response Theory package for the R environment. Journal of Statistical Software, 48(6), 1-29.

Curcio, A. L., Mak, A. S., \& Knott, V. E. (2015). The Australian Self-report Delinquency Scale: A revision. Australian Journal of Psychology, 67(3), 166-177, doi:10.1111/ajpy.12075.

DeLisi, M., \& Piquero, A. R. (2011). New frontiers in criminal careers research, 2000-2011: A state-of-the-art review. Journal of Criminal Justice, 39(4), 289-301, doi:10.1016/j.jcrimjus.2011.05.001.

Elliott, D. S., Huizinga, D., \& Ageton, S. S. (1985). Explaining delinquency and drug use. Beverly Hills, CA: Sage.

Elonheimo, H., Gyllenberg, D., Huttunen, J., Ristkari, T., Sillanmäki, L., \& Sourander, A. (2014). Criminal offending among males and females between ages 15 and 30 in a population-based nationwide 1981 birth cohort: Results from the FinnCrime Study. Journal of Adolescence, 37(8), 1269-1279, doi:10.1016/j.adolescence.2014.09.005.

Enzmann, D., Marshall, I. H., Killias, M., Junger-Tas, J., Steketee, M., \& Gruszczynska, B. (2010). Selfreported youth delinquency in Europe and beyond: First results of the Second International Self-Report Delinquency Study in the context of police and victimization data. European Journal of Criminology, 7(2), 159-183, doi:10.1177/1477370809358018.

Farrington, D. P., \& Ttofi, M. M. (2014). Criminal careers in self-reports compared with official records. Criminal Behaviour and Mental Health, 24(4), 225-228, doi:10.1002/cbm.1932.

Flesch, R. (1948). A new readability yardstick. Journal of Applied Psychology, 32(3), 221-233.

Gatti, U., Soellner, R., Schadee, H. M. A., Verde, A., \& Rocca, G. (2013). Effects of Delinquency on Alcohol use Among Juveniles in Europe: Results from the ISRD-2 Study. European Journal on Criminal Policy and Research, 19(2), 153-170, doi:10.1007/s10610-013-9202-x.

Harwell, M., Stone, C. A., Hsu, T.-C., \& Kirisci, L. (1996). Monte Carlo Studies in Item Response Theory. Applied Psychological Measurement, 20(2), 101-125, doi:10.1177/014662169602000201. 
Jolliffe, D., Farrington, D. P., Piquero, A. R., MacLeod, J. F., \& van de Weijer, S. (2017). Prevalence of lifecourse-persistent, adolescence-limited, and late-onset offenders: A systematic review of prospective longitudinal studies. Aggression and Violent Behavior, 33, 4-14, doi:10.1016/j.avb.2017.01.002.

Junger-Tas, J., \& Marshall, I. H. (1999). The self-report methodology in crime research. Crime and Justice: A Review of Research, 25, 291-368, doi:10.1086/449291.

Kang, T., \& Chen, T. T. (2008). Performance of the Generalized S-X2 Item Fit Index for Polytomous IRT Models. Journal of Educational Measurement, 45(4), 391-406, doi:10.1111/j.1745-3984.2008.00071.x.

Krohn, M. D., Thornberry, T. P., Gibson, C. L., \& Baldwin, J. M. (2010). The Development and Impact of SelfReport Measures of Crime and Delinquency. Journal of Quantitative Criminology, 26(4), 509-525, doi:10.1007/s10940-010-9119-1.

Le Blanc, M., \& Bouthillier, C. (2003). A developmental test of the general deviance syndrome with adjudicated girls and boys using hierarchical confirmatory factor analysis. Criminal Behaviour and Mental Health, 13, 81-105.

Loeber, R., Menting, B., Lynam, D. R., Moffitt, T. E., Stouthamer-Loeber, M., Stallings, R., et al. (2012). Findings from the Pittsburgh Youth Study: Cognitive impulsivity and intelligence as predictors of the age-crime curve. Journal of the American Academy of Child \& Adolescent Psychiatry, 51(11), 11361149, doi:10.1016/j.jaac.2012.08.019.

McDonald, R. P. (1999). Test theory: A unified treatment. New York: Psychology Press.

Moffitt, T. E. (2006a). Life-course-persistent versus adolescence-limited antisocial behavior. In D. Cicchetti, \& D. J. Cohen (Eds.), Developmental Psychopathology (2nd ed., Vol. 3, pp. 570-598). Newark: John Wiley \& Sons, Inc.

Moffitt, T. E. (2006b). A review of research on the taxonomy of life-course persistent versus adolescencelimited antisocial behavior. In F. T. Cullen, J. P. Wright, \& K. R. Blevins (Eds.), Taking stock: The status of criminological theory (pp. 277-311, Advances in Criminological Theory, Vol. 15). New Brunswick: Transaction Publishers.

Moffitt, T. E. (2018). Male antisocial behaviour in adolescence and beyond. Nature Human Behaviour, 2(3), 177-186, doi:10.1038/s41562-018-0309-4.

Moffitt, T. E., Caspi, A., Harrington, H., \& Milne, B. J. (2002). Males on the Life-Course-Persistent and Adolescence-Limited Antisocial Pathways: Follow-Up at Age 26 Years. Development and Psychopathology, 14(1), 179-207, doi:10.1017/S0954579402001104.

Orlando, M., \& Thissen, D. (2000). Likelihood-Based Item-Fit Indices for Dichotomous Item Response Theory Models. Applied Psychological Measurement, 24(1), 50-64, doi:10.1177/01466216000241003.

Orlando, M., \& Thissen, D. (2003). Further Investigation of the Performance of S - X2: An Item Fit Index for Use With Dichotomous Item Response Theory Models. Applied Psychological Measurement, 27(4), 289-298, doi:10.1177/0146621603027004004.

Osgood, D. W., McMorris, B. J., \& Potenza, M. T. (2002). Analyzing Multiple-Item Measures of Crime and Deviance I: Item Response Theory Scaling. Journal of Quantitative Criminology, 18(3), 267-296, doi:10.1023/A:1016008004010.

Piquero, A. R., Farrington, D. P., \& Blumstein, A. (2007). Key Issues in Criminal Career Research: New Analyses of the Cambridge Study in Delinquent Development. Cambridge: Cambridge University Press.

Piquero, A. R., MacIntosh, R., \& Hickman, M. (2002). The Validity of a Self-Reported Delinquency Scale: Comparisons Across Gender, Age Race, and Place of Residence. Sociological Methods \& Research, 30(4), 492-529, doi:10.1177/0049124102030004002.

Pulkkinen, L., Lyyra, A.-L., \& Kokko, K. (2009). Life success of males on nonoffender, adolescence-limited, persistent, and adult-onset antisocial pathways: Follow-up from age 8 to 42. Aggressive Behavior, 35(2), 117-135, doi:10.1002/ab.20297.

R Core Team (2017). R: A language and environment for statistical computing. Vienna, Austria: R Foundation for Statistical Computing.

Raudenbush, S. W., Johnson, C., \& Sampson, R. J. (2003). A Multivariate, Multilevel Rasch Model with Application to Self-Reported Criminal Behavior. Sociological Methodology, 33(1), 169-211, doi:10.1111/j.0081-1750.2003.t01-1-00130.x.

Revelle, W. (2017). psych: Procedures for personality and psychological research. (1.7.5 ed.). Evanston, Illinois, USA: Northwestern University.

Roisman, G. I., Monahan, K. C., Campbell, S. B., Steinberg, L., \& Cauffman, E. (2010). Is adolescence-onset antisocial behavior developmentally normative? Development and Psychopathology, 22(2), 295-311, doi:10.1017/S0954579410000076.

Rutter, M. (2003). Commentary: Causal processes leading to antisocial behavior. Developmental Psychology, $39(2), 372-378$. 
Samejima, F. (1969). Estimation of latent ability using a response pattern of graded scores. Psychometrika Monograph, 17(4p2), 1-\&.

Snow, P. C., \& Powell, M. B. (2012). Youth (in)justice: Oral language competence in early life and risk for engagement in antisocial behaviour in adolescence. Trends \& Issues in Crime and Criminal Justice, 435.

Stewart, A., Allard, T., Gray, B., \& Ogilvie, J. (2007). Understanding initiation of offending and recidivism across the juvenile and adult justice systems. Brisbane, Australia: Justice Modelling @ Griffith, Griffith University.

Stolzenberg, L., \& D'Alessio, S. J. (2008). Co-Offending and the Age-Crime Curve. Journal of Research in Crime and Delinquency, 45(1), 65-86, doi:10.1177/0022427807309441.

Stout, W. F. (1990). A new item response theory modeling approach with applications to unidimensionality assessment and ability estimation. Psychometrika, 55(2), 293-325, doi:10.1007/BF02295289.

The National Health and Medical Research Council (2015). National Statement on Ethical Conduct in Human Research 2007. In Australian Research Council and the Australian Vice-Cancellors' Committee (Ed.). Canberra: Commonwealth of Australia.

Thissen, D., Pommerich, M., Billeaud, K., \& Williams, V. S. L. (1995). Item Response Theory for Scores on Tests Including Polytomous Items with Ordered Responses. Applied Psychological Measurement, 19(1), 39-49, doi:10.1177/014662169501900105.

Tremblay, R. E. (2010). Developmental origins of disruptive behaviour problems: The 'original sin' hypothesis, epigenetics and their consequences for prevention. Journal of Child Psychology and Psychiatry, 51(4), 341-367, doi:10.1111/j.1469-7610.2010.02211.x.

Warr, M. (2002). Companions in crime: The social aspects of criminal conduct. Cambridge: Cambridge University Press. 
Table 1.

Demographic characteristics of the sample

\begin{tabular}{|c|c|c|c|c|}
\hline \multirow[t]{2}{*}{ Variable } & \multicolumn{2}{|c|}{ Sex } & \multirow{2}{*}{$\begin{array}{c}\text { Total } \\
\text { Percent }\end{array}$} & \multirow[t]{2}{*}{$\chi^{2} \dagger$} \\
\hline & Female & Male & & \\
\hline Total participants & 262 & 142 & & \\
\hline \multicolumn{5}{|l|}{ Ethnicity } \\
\hline Indigenous Australian & 5 & 2 & 1.7 & $n s$ \\
\hline Caucasian & 202 & 111 & 77.5 & \\
\hline Asian & 26 & 15 & 10.1 & \\
\hline Other & 29 & 14 & 10.6 & \\
\hline \multicolumn{5}{|l|}{ Highest level of education } \\
\hline Grade 10 & 8 & 4 & 3.0 & $n s$ \\
\hline Grade 12 & 213 & 118 & 81.9 & \\
\hline Undergraduate degree & 21 & 8 & 7.2 & \\
\hline Postgraduate degree & 1 & 1 & 0.5 & \\
\hline Diploma & 17 & 10 & 6.7 & \\
\hline Other & 2 & 1 & 0.7 & \\
\hline Diagnosed mental illness & 40 & 10 & 12.4 & $5.75^{*}$ \\
\hline Substance use disorder & 1 & 1 & 0.5 & \\
\hline Mood disorder & 27 & 8 & 8.7 & \\
\hline Anxiety disorder & 24 & 6 & 7.4 & \\
\hline Schizophrenia & 1 & 0 & 0.2 & \\
\hline Personality & 0 & 0 & 0.0 & \\
\hline Eating disorder & 6 & 0 & 1.5 & \\
\hline Disorder diagnosed in childhood & 1 & 1 & 0.5 & \\
\hline Other diagnosis & 0 & 1 & 0.2 & \\
\hline Head injury requiring hospitalization & 17 & 15 & 7.9 & $n s$ \\
\hline Justice system contact & 16 & 23 & 9.7 & $10.75 * *$ \\
\hline
\end{tabular}

$\dagger$ Chi-square test examining differences in the distribution of sex across levels of each variable

$* p<.05, * * p<.001$ 
Table 2.

Descriptive information for summed 12-month frequency antisocial behaviour scale categories

\begin{tabular}{|c|c|c|c|c|c|c|c|c|c|c|c|}
\hline \multirow[t]{2}{*}{ Category } & \multirow[t]{2}{*}{$\begin{array}{l}\text { Number } \\
\text { of items }\end{array}$} & \multicolumn{2}{|c|}{$\begin{array}{c}\text { Mean } \\
(S D)\end{array}$} & \multirow[t]{2}{*}{ Min } & \multirow[t]{2}{*}{$\operatorname{Max}$} & \multirow[t]{2}{*}{ Mode } & \multirow[t]{2}{*}{$\begin{array}{c}\% \text { zero } \\
\text { responses }\end{array}$} & \multirow[t]{2}{*}{ Skewness } & \multirow[t]{2}{*}{ Kurtosis } & \multicolumn{2}{|c|}{$H^{\dagger}$} \\
\hline & & Male & Female & & & & & & & Age & Sex \\
\hline $\begin{array}{l}\text { General } \\
\text { rule } \\
\text { breaking }\end{array}$ & 28 & $\begin{array}{c}35.97 \\
(24.09)\end{array}$ & $\begin{array}{c}32.80 \\
(21.22)\end{array}$ & 0 & 132 & 20 & 0.5 & $1.18 *$ & $1.86^{*}$ & $n s$ & $n s$ \\
\hline Aggressive & 13 & $\begin{array}{c}4.51 \\
(8.95)\end{array}$ & $\begin{array}{c}3.05 \\
(5.95)\end{array}$ & 0 & 60 & 0 & 48.0 & $4.13 *$ & $22.32 *$ & $n s$ & $n s$ \\
\hline Vehicle & 9 & $\begin{array}{c}7.31 \\
(7.55)\end{array}$ & $\begin{array}{c}5.58 \\
(6.36)\end{array}$ & 0 & 42 & 0 & 24.5 & $1.85 *$ & $4.84 *$ & $n s$ & $5.72 *$ \\
\hline Substance & 9 & $\begin{array}{c}14.37 \\
(10.71)\end{array}$ & $\begin{array}{c}15.18 \\
(10.42)\end{array}$ & 0 & 48 & 18 & 8.9 & $0.45 *$ & $-0.24 *$ & $11.50 *$ & $n s$ \\
\hline Theft & 11 & $\begin{array}{c}1.26 \\
(4.08)\end{array}$ & $\begin{array}{c}0.99 \\
(2.72)\end{array}$ & 0 & 38 & 0 & 75.2 & $5.77 *$ & $47.60 *$ & $n s$ & $n s$ \\
\hline Property & 8 & $\begin{array}{c}2.07 \\
(5.22)\end{array}$ & $\begin{array}{c}1.08 \\
(3.08)\end{array}$ & 0 & 41 & 0 & 68.3 & $5.73 *$ & $41.89^{*}$ & $13.20 *$ & $8.02 * *$ \\
\hline Technology & 4 & $\begin{array}{c}4.85 \\
(4.37)\end{array}$ & $\begin{array}{c}3.91 \\
(4.41)\end{array}$ & 0 & 24 & 0 & 32.4 & $1.29 *$ & $2.09 *$ & $n s$ & $7.08 * *$ \\
\hline Sexual & 4 & $\begin{array}{c}2.98 \\
(3.72)\end{array}$ & $\begin{array}{c}3.84 \\
(4.30)\end{array}$ & 0 & 24 & 0 & 41.06 & $1.06 *$ & 0.66 & $13.10^{*}$ & $4.70 *$ \\
\hline Total & 86 & $\begin{array}{c}73.31 \\
(52.98)\end{array}$ & $\begin{array}{c}66.42 \\
(44.42)\end{array}$ & 0 & 366 & 37 & 0.3 & $2.00 *$ & $7.53 *$ & $n s$ & $n s$ \\
\hline
\end{tabular}

$\dagger$ Series of Kruskal-Wallis $H$ tests examining age and sex mean differences for each ASB category mean summed scale score: Age $d f(5,397)$; Sex $d f(1,397)$.

$* p<.05, * * p<.01$ 
Table 3.

Spearman's nonparametric correlation matrix for mean summed antisocial behaviour category scores.

\begin{tabular}{|c|c|c|c|c|c|c|c|}
\hline & 1 & 2 & 3 & 4 & 5 & 6 & 7 \\
\hline \multicolumn{8}{|l|}{ 1. General } \\
\hline 2. Aggressive & $0.59 * * *$ & & & & & & \\
\hline 3. Vehicle & $0.61 * * *$ & $0.41 * * *$ & & & & & \\
\hline 4. Substance & $0.42 * * *$ & $0.23 * * *$ & $0.37 * * *$ & & & & \\
\hline 5. Theft & $0.39 * * *$ & $0.28 * * *$ & $0.39 * * *$ & $0.32 * * *$ & & & \\
\hline 6. Property & $0.52 * * *$ & $0.35 * * *$ & $0.43 * * *$ & $0.31 * * *$ & $0.48 * * *$ & & \\
\hline 7. Technology & $0.44 * * *$ & $0.33 * * *$ & $0.31 * * *$ & $0.26 * * *$ & $0.27 * * *$ & $0.38 * * *$ & \\
\hline 8. Sexual & $0.37 * * *$ & $0.26 * * *$ & $0.34 * * *$ & $0.41 * * *$ & $0.25 * * *$ & $0.20 * * *$ & $0.26 * * *$ \\
\hline
\end{tabular}

$* p<.05, * * p<.01, * * * p<.001$. 
Table 4.

Item response theory final model parameters for antisocial behaviour scale categories

\begin{tabular}{|c|c|c|c|}
\hline \multicolumn{4}{|l|}{ Category/item } \\
\hline Status / general delinquency / rule breaking & $\begin{array}{c}\alpha \\
\text { Discrimination }\end{array}$ & $\begin{array}{c}\beta_{1} \\
1-3 \text { times }\end{array}$ & $\begin{array}{c}\beta_{2} \\
4 \text { or more } \\
\text { times }\end{array}$ \\
\hline Disrupted people's games/work & 1.07 & 0.53 & 2.49 \\
\hline Disrupted colleagues & 0.95 & 1.32 & 2.36 \\
\hline Sworn at others or called names & 1.05 & -1.15 & 0.25 \\
\hline Not completed class or work tasks & 1.14 & -0.64 & 1.22 \\
\hline Teased or made fun of someone else & 1.23 & -0.48 & 1.01 \\
\hline Not paid proper fee & 1.10 & 0.48 & 2.34 \\
\hline Been late for work & 0.99 & -2.35 & 0.37 \\
\hline Missed a day of work without excuse & 0.98 & -1.26 & 0.87 \\
\hline Done something against caregivers will & 1.69 & -0.64 & 0.80 \\
\hline Tricked or pranked & 1.33 & 1.41 & 2.90 \\
\hline Made abusive phone calls & 1.91 & 2.02 & 3.55 \\
\hline Been warned by police but not arrested & 0.87 & 2.72 & 6.55 \\
\hline Told a lie & 1.38 & -2.48 & -0.35 \\
\hline Deliberately spread rumors & 1.98 & 1.63 & 2.75 \\
\hline Lied to have a sickie & 1.41 & -0.48 & 1.27 \\
\hline Carry a weapon & 0.98 & 3.60 & 4.59 \\
\hline Gambling & 0.55 & -0.11 & 2.29 \\
\hline Cheated on exam or assignment & 1.11 & 1.43 & 3.57 \\
\hline Discrimination & 0.95 & 1.75 & 2.67 \\
\hline Accept gifts and go with strangers & 0.89 & 2.37 & 4.55 \\
\hline Run away from home & 1.42 & 2.95 & 3.76 \\
\hline Stay out past curfew & 1.62 & 1.01 & 1.58 \\
\hline Encourage others to break rules & 2.15 & 0.35 & 1.43 \\
\hline Lied to caregivers about whereabouts & 1.88 & -0.15 & 0.90 \\
\hline \multirow[t]{8}{*}{ Encouraged others to hurt someone } & 1.92 & 1.85 & 2.56 \\
\hline & Overall & Log & -6744.86 \\
\hline & Model Fit: & Likelihood & \\
\hline & & AIC & 13639.73 \\
\hline & & BIC & 13939.83 \\
\hline & $\alpha$ & $\beta_{1}$ & $\beta_{2}$ \\
\hline & Discrimination & $1-3$ times & 4 or more \\
\hline & & & times \\
\hline Hit pushed punched or slapped someone & 2.38 & 0.35 & 1.70 \\
\hline Deliberately hurt or beat up someone & 3.67 & 1.44 & 2.32 \\
\hline Taken part in group fight & 2.78 & 2.09 & 2.60 \\
\hline Physical abuse toward partner & 1.18 & 2.40 & 3.52 \\
\hline Thrown objects at people & 1.58 & 2.68 & 3.36 \\
\hline Deliberately hit caregivers & 1.87 & 2.59 & 3.73 \\
\hline Deliberately hit siblings & 1.29 & 1.23 & 2.41 \\
\hline Verbally or physically threaten someone & 2.56 & 0.96 & 1.70 \\
\hline \multirow[t]{8}{*}{ Physical force to dominate } & 3.96 & 1.40 & 1.85 \\
\hline & Overall & Log & -1304.58 \\
\hline & Model Fit: & Likelihood & \\
\hline & & AIC & 2663.15 \\
\hline & & BIC & 2771.19 \\
\hline & $\alpha$ & $\beta_{1}$ & $\beta_{2}$ \\
\hline & Discrimination & $1-3$ times & 4 or more \\
\hline & & & times \\
\hline Driven vehicle without license & 1.81 & 1.61 & 2.53 \\
\hline Drunk driving & 1.61 & 1.61 & 3.00 \\
\hline
\end{tabular}




\begin{tabular}{|c|c|c|c|}
\hline Taken vehicle without permission & 1.18 & 3.98 & 5.08 \\
\hline Joyride in stolen car & 1.33 & 3.92 & 4.64 \\
\hline Driven at high speeds & 0.96 & -0.23 & 0.81 \\
\hline Raced other vehicles & 1.80 & 1.51 & 2.47 \\
\hline Driven in unregistered vehicle & 2.21 & 2.05 & 3.08 \\
\hline Ride in vehicle without seatbelt & 1.63 & 0.47 & 1.47 \\
\hline \multirow[t]{8}{*}{ Ride without helmet } & 1.48 & 0.51 & 1.36 \\
\hline & Overall & Log & -1735.66 \\
\hline & Model Fit: & Likelihood & \\
\hline & & AIC & 3525.32 \\
\hline & & BIC & 3633.36 \\
\hline & $\alpha$ & $\beta_{1}$ & $\beta_{2}$ \\
\hline & Discrimination & $1-3$ times & 4 or more \\
\hline & & & \\
\hline Drunk alcohol & 2.06 & -1.66 & -0.91 \\
\hline Smoked cigarettes & 2.60 & 0.42 & 0.81 \\
\hline Used cannabis & 3.20 & 0.45 & 1.13 \\
\hline Used amphetamines & 3.06 & 1.24 & 1.72 \\
\hline \multirow[t]{8}{*}{ Push or sold drugs } & 5.41 & 1.72 & 2.20 \\
\hline & Overall & Log & -1098.90 \\
\hline & Model Fit: & Likelihood & \\
\hline & & AIC & 2227.80 \\
\hline & & BIC & 2287.82 \\
\hline & $\alpha$ & $\beta_{1}$ & $\beta_{2}$ \\
\hline & Discrimination & $1-3$ times & 4 or more \\
\hline & & & times \\
\hline Shoplifted & 2.43 & 1.79 & 2.46 \\
\hline Stolen less than $\$ 50$ & 3.25 & 1.43 & 2.26 \\
\hline Cheated on machines & 1.03 & 2.71 & 4.96 \\
\hline Bought used or sold something stolen & 1.40 & 2.26 & 3.77 \\
\hline \multirow[t]{8}{*}{ Stolen employer property } & 1.60 & 2.67 & 3.79 \\
\hline & Overall & $\log$ & -562.32 \\
\hline & Model Fit: & Likelihood & \\
\hline & & AIC & 1154.64 \\
\hline & & BIC & 1214.66 \\
\hline & $\alpha$ & $\beta_{1}$ & $\beta_{2}$ \\
\hline & Discrimination & $1-3$ times & 4 or more \\
\hline & & & times \\
\hline Deliberate destruction of things that don't belong to you & 2.12 & 1.39 & 2.74 \\
\hline Deliberately messed up other's property & 3.61 & 1.95 & 2.55 \\
\hline Deliberately damaged public property & 3.71 & 1.60 & 2.47 \\
\hline Graffiti in public spaces & 2.16 & 1.77 & 3.00 \\
\hline Entered premises without permission & 2.09 & 1.16 & 2.22 \\
\hline \multirow{8}{*}{ Deliberately damaged property in own home } & 1.49 & 2.24 & 3.80 \\
\hline & Overall & $\log$ & -731.49 \\
\hline & Model Fit: & Likelihood & \\
\hline & & AIC & 1498.97 \\
\hline & & BIC & 1571.00 \\
\hline & $\alpha$ & $\beta_{1}$ & $\beta_{2}$ \\
\hline & Discrimination & $1-3$ times & 4 or more \\
\hline & & & times \\
\hline Download copyrighted material & 0.71 & -0.68 & 0.23 \\
\hline Cyber-bullying & 1.60 & 2.13 & 2.99 \\
\hline Impersonate online & 3.94 & 1.09 & 1.68 \\
\hline Hacked personal accounts & 1.84 & 1.34 & 2.13 \\
\hline
\end{tabular}




\begin{tabular}{|c|c|c|c|}
\hline & $\begin{array}{l}\text { Overall } \\
\text { Model Fit: }\end{array}$ & $\begin{array}{c}\text { Log } \\
\text { Likelihood } \\
\text { AIC } \\
\text { BIC }\end{array}$ & $\begin{array}{l}-921.62 \\
1867.24 \\
1915.26\end{array}$ \\
\hline Sexual-related & $\begin{array}{c}\alpha \\
\text { Discrimination }\end{array}$ & $\begin{array}{c}\beta_{1} \\
1-3 \text { times }\end{array}$ & $\begin{array}{c}\beta_{2} \\
4 \text { or more } \\
\text { times }\end{array}$ \\
\hline $\begin{array}{l}\text { Unprotected sex } \\
\text { Sexting }\end{array}$ & $\begin{array}{c}4.07 \\
1.10 \\
\text { Overall } \\
\text { Model Fit: }\end{array}$ & $\begin{array}{c}0.14 \\
0.47 \\
\text { Log } \\
\text { Likelihood } \\
\text { AIC } \\
\text { BIC } \\
\end{array}$ & $\begin{array}{c}0.65 \\
1.42 \\
-751.07 \\
\\
1514.14 \\
1538.15 \\
\end{array}$ \\
\hline
\end{tabular}


Table 5 .

Factorial analysis of variance results examining the effects of age and sex on mean composite factor scores for antisocial behaviour categories

\begin{tabular}{|c|c|c|c|c|c|}
\hline Source & SS & $d f$ & MS & $F$ & Partial $\eta^{2}$ \\
\hline \multicolumn{6}{|l|}{ General } \\
\hline Sex & 0.80 & 1 & 0.84 & 1.00 & $>.01$ \\
\hline Age & 13.00 & 5 & 2.59 & $3.09 * *$ & .04 \\
\hline Sex x Age & 0.90 & 5 & 0.19 & 0.22 & $>.01$ \\
\hline Error & 329.10 & 392 & 0.84 & & \\
\hline \multicolumn{6}{|l|}{ Aggressive } \\
\hline Sex & 1.15 & 1 & 1.15 & 1.87 & $>.01$ \\
\hline Age & 3.58 & 5 & 0.72 & 1.16 & .01 \\
\hline Sex x Age & 1.19 & 5 & 0.24 & 0.39 & $>.01$ \\
\hline Error & 241.70 & 392 & 0.62 & & \\
\hline \multicolumn{6}{|l|}{ Vehicle } \\
\hline Sex & 3.72 & 1 & 3.72 & $6.18^{*}$ & .02 \\
\hline Age & 4.98 & 5 & 1.00 & 1.65 & .02 \\
\hline Sex x Age & 1.49 & 5 & 0.30 & 0.49 & .01 \\
\hline Error & 236.38 & 392 & 0.60 & & \\
\hline \multicolumn{6}{|l|}{ Substance } \\
\hline Sex & 0.50 & 1 & 0.50 & 0.67 & $>.01$ \\
\hline Age & 5.78 & 5 & 1.16 & 1.54 & .02 \\
\hline Sex x Age & 2.36 & 5 & 0.47 & 0.63 & .01 \\
\hline Error & 294.03 & 392 & 0.75 & & \\
\hline \multicolumn{6}{|l|}{ Theft } \\
\hline Sex & 0.04 & 1 & 0.04 & 0.10 & $>.01$ \\
\hline Age & 0.92 & 5 & 0.18 & 0.48 & .01 \\
\hline Sex x Age & 0.73 & 5 & 0.15 & 0.38 & $>.01$ \\
\hline Error & 150.35 & 392 & 0.38 & & \\
\hline \multicolumn{6}{|l|}{ Property } \\
\hline Sex & 3.72 & 1 & 3.72 & $8.03 * *$ & .02 \\
\hline Age & 7.00 & 5 & 1.40 & $3.02 *$ & .04 \\
\hline Sex x Age & 1.62 & 5 & 0.32 & 0.70 & .01 \\
\hline Error & 181.66 & 392 & 0.46 & & \\
\hline \multicolumn{6}{|l|}{ Technology } \\
\hline Sex & 2.43 & 1 & 2.43 & $5.57^{*}$ & .01 \\
\hline Age & 3.94 & 5 & 0.79 & 1.81 & .02 \\
\hline Sex x Age & 1.18 & 5 & 0.24 & 0.54 & .01 \\
\hline Error & 170.92 & 392 & 0.44 & & \\
\hline \multicolumn{6}{|l|}{ Sexual } \\
\hline Sex & 3.41 & 1 & 3.41 & $6.28^{*}$ & .02 \\
\hline Age & 5.99 & 5 & 1.20 & 2.21 & .03 \\
\hline Sex x Age & 2.11 & 5 & 0.78 & 0.57 & .01 \\
\hline Error & 212.97 & 392 & 0.54 & & \\
\hline
\end{tabular}


Table A1.

Descriptive information for scale items

\begin{tabular}{|c|c|c|c|c|c|}
\hline \multirow[t]{2}{*}{ Subcategory and item } & \multicolumn{4}{|c|}{ 12-month frequency } & \multirow{2}{*}{$\begin{array}{c}\text { McDonald's } \\
\omega\end{array}$} \\
\hline & Mean & $\mathrm{SD}$ & Mode & Skewness & \\
\hline Status / general delinquency / rule breaking & & & & & .88 \\
\hline Disrupted people's games/work & 1.02 & 1.69 & 0 & $1.79 *$ & \\
\hline Disrupted colleagues & 0.92 & 1.83 & 0 & $1.91 *$ & \\
\hline Fired from work or university & 0.05 & 0.26 & 0 & $6.60 *$ & \\
\hline Talked back impolitely & 0.38 & 1.12 & 0 & $3.61 *$ & \\
\hline Sworn at others or called names & 3.09 & 2.53 & 6 & 0.01 & \\
\hline Not completed class or work tasks & 2.13 & 2.21 & 0 & $0.67 *$ & \\
\hline Teased or made fun of someone else & 2.13 & 2.30 & 0 & $0.69 *$ & \\
\hline Not paid proper fee & 1.07 & 1.78 & 0 & $1.80^{*}$ & \\
\hline Been late for work & 3.26 & 2.07 & 6 & 0.01 & \\
\hline Missed a day of work without excuse & 2.55 & 2.22 & 0 & $0.39 *$ & \\
\hline Done something against caregivers will & 2.28 & 2.25 & 0 & $0.58 *$ & \\
\hline Tricked or pranked & 0.46 & 1.22 & 0 & $3.21 *$ & \\
\hline Made abusive phone calls & 0.15 & 0.68 & 0 & $6.10^{*}$ & \\
\hline Been warned by police but not arrested & 0.16 & 0.58 & 0 & $5.64 *$ & \\
\hline Appeared in court & 0.04 & 0.20 & 0 & $5.79 *$ & \\
\hline Told a lie & 4.11 & 2.09 & 6 & $-0.54 *$ & \\
\hline Deliberately spread rumors & 0.26 & 0.89 & 0 & $3.99 *$ & \\
\hline Lied to have a sickie & 1.86 & 2.03 & 0 & $0.89 *$ & \\
\hline Carry a weapon & 0.14 & 0.80 & 0 & $6.60 *$ & \\
\hline Gambling & 1.83 & 2.29 & 0 & $0.89 *$ & \\
\hline Cheated on exam or assignment & 0.49 & 1.16 & 0 & $3.03 *$ & \\
\hline Discrimination & 0.75 & 1.74 & 0 & $2.27 *$ & \\
\hline Accept gifts and go with strangers & 0.32 & 1.02 & 0 & $3.90^{*}$ & \\
\hline Run away from home & 0.11 & 0.72 & 0 & $7.29 *$ & \\
\hline Stay out past curfew & 0.98 & 1.97 & 0 & $1.83^{*}$ & \\
\hline Encourage others to break rules & 1.16 & 1.82 & 0 & $1.53 *$ & \\
\hline Lied to caregivers whereabouts & 1.98 & 2.31 & 0 & $0.76^{*}$ & \\
\hline Encouraged others to hurt someone & 0.26 & 1.04 & 0 & $4.48 *$ & \\
\hline Aggression & & & & & .86 \\
\hline Hit pushed punched or slapped someone & 0.96 & 1.64 & 0 & $2.02 *$ & \\
\hline Deliberately hurt or beat up someone & 0.21 & 0.86 & 0 & $5.27 *$ & \\
\hline Taken part in group fist fight & 0.11 & 0.75 & 0 & $7.40 *$ & \\
\hline Used a weapon in a fight & 0.03 & 0.34 & 0 & $15.25 *$ & \\
\hline Used forced to get money or property & 0.06 & 0.44 & 0 & $9.48 *$ & \\
\hline Physical abuse toward partner & 0.25 & 0.97 & 0 & $4.68^{*}$ & \\
\hline Beat someone up who did nothing to you & 0.02 & 0.31 & 0 & $17.78 *$ & \\
\hline Thrown objects at people & 0.13 & 0.78 & 0 & $6.82 *$ & \\
\hline Deliberately hurt animal & 0.07 & 0.60 & 0 & $9.49 *$ & \\
\hline Deliberately hit caregivers & 0.07 & 0.50 & 0 & $9.52 *$ & \\
\hline Deliberately hit siblings & 0.67 & 1.49 & 0 & $2.42 *$ & \\
\hline Verbally or physically threaten someone & 0.67 & 1.57 & 0 & $2.52 *$ & \\
\hline Physical force to dominate & 0.33 & 1.19 & 0 & $4.01 *$ & \\
\hline Vehicle-related & & & & & .72 \\
\hline Driven vehicle without license & 0.35 & 1.17 & 0 & $3.84 *$ & \\
\hline Drunk driving & 0.30 & 0.96 & 0 & $4.03 *$ & \\
\hline Taken vehicle without permission & 0.04 & 0.41 & 0 & $11.32 *$ & \\
\hline Joyride in stolen car & 0.03 & 0.36 & 0 & $11.60 *$ & \\
\hline Driven at high speeds & 2.36 & 2.56 & 0 & $0.46^{*}$ & \\
\hline Raced other vehicles & 0.35 & 1.08 & 0 & $3.56^{*}$ & \\
\hline Driven in unregistered vehicle & 0.11 & 0.58 & 0 & $7.53 *$ & \\
\hline Ride in vehicle without seatbelt & 1.24 & 1.99 & 0 & $1.47^{*}$ & \\
\hline Ride without helmet & 1.39 & 2.20 & 0 & $1.32 *$ & \\
\hline
\end{tabular}




\begin{tabular}{|c|c|c|c|c|c|}
\hline Substance use & & & & & .80 \\
\hline Sniffed substance on purpose & 0.09 & 0.61 & 0 & $7.72 *$ & \\
\hline Drunk alcohol & 4.72 & 2.12 & 6 & $-1.34 *$ & \\
\hline Drunk alcohol in unlicensed place & 2.97 & 2.69 & 6 & 0.04 & \\
\hline Smoked cigarettes & 1.68 & 2.49 & 0 & $1.00^{*}$ & \\
\hline Used cannabis & 1.28 & 2.12 & 0 & $1.44 *$ & \\
\hline Used amphetamines & 0.51 & 1.47 & 0 & $3.02 *$ & \\
\hline Used other hard drugs & 0.06 & 0.54 & 0 & $10.21 *$ & \\
\hline Push or sold drugs & 0.16 & 0.79 & 0 & $5.87 *$ & \\
\hline Binge drinking & 3.43 & 2.71 & 6 & $-0.29 *$ & \\
\hline Theft & & & & & $.80^{1}$ \\
\hline Shoplifted & 0.24 & 1.01 & 0 & $4.93 *$ & \\
\hline Stolen $\$ 50$ or more & 0.11 & 0.64 & 0 & $7.45^{*}$ & \\
\hline Stolen less than $\$ 50$ & 0.26 & 0.97 & 0 & $4.57 *$ & \\
\hline $\begin{array}{l}\text { Broken into premises with intention of } \\
\text { stealing }\end{array}$ & 0.01 & 0.13 & 0 & $11.86^{*}$ & \\
\hline Cheated on machines & 0.16 & 0.63 & 0 & $5.20^{*}$ & \\
\hline Bought used or sold something stolen & 0.17 & 0.74 & 0 & $5.97 *$ & \\
\hline Stolen employer property & 0.09 & 0.55 & 0 & $8.46^{*}$ & \\
\hline Taken part in robbery & 0.00 & 0.00 & 0 & . & \\
\hline Stolen from bicycle & 0.02 & 0.31 & 0 & $18.70 *$ & \\
\hline Stolen from car or motorbike & 0.02 & 0.31 & 0 & $17.47 *$ & \\
\hline Stolen car to sell it & 0.00 & 0.00 & 0 & - & \\
\hline Property & & & & & .84 \\
\hline $\begin{array}{l}\text { Deliberate destruction of things that don't } \\
\text { belong to you }\end{array}$ & 0.30 & 0.97 & 0 & $4.48^{*}$ & \\
\hline Deliberately messed up other's property & 0.11 & 0.70 & 0 & $7.35^{*}$ & \\
\hline Set fire to property & 0.02 & 0.21 & 0 & $11.49 *$ & \\
\hline Deliberately damaged public property & 0.17 & 0.74 & 0 & $5.59 *$ & \\
\hline Deliberately damage work property & 0.04 & 0.44 & 0 & $12.83 *$ & \\
\hline Graffiti in public spaces & 0.19 & 0.76 & 0 & $5.12^{*}$ & \\
\hline Entered premises without permission & 0.46 & 1.19 & 0 & $3.06^{*}$ & \\
\hline Deliberately damaged property in own home & 0.15 & 0.67 & 0 & $6.12^{*}$ & \\
\hline Technology-related & & & & & .60 \\
\hline Download copyrighted material & 2.98 & 2.76 & 6 & 0.03 & \\
\hline Cyber-bullying & 0.23 & 0.98 & 0 & $5.08^{*}$ & \\
\hline Impersonate online & 0.51 & 1.42 & 0 & $3.01 *$ & \\
\hline Hacked personal accounts & 0.51 & 1.43 & 0 & $3.03 *$ & \\
\hline Sexual-related & & & & & .62 \\
\hline Unprotected sex & 1.88 & 2.50 & 0 & $0.84 *$ & \\
\hline Have sex for means & 0.04 & 0.42 & 0 & $11.77 *$ & \\
\hline Force sex & 0.02 & 0.31 & 0 & $17.78^{*}$ & \\
\hline Sexting & 1.59 & 2.32 & 0 & $1.11 *$ & \\
\hline
\end{tabular}

$* p<.05$
${ }^{*}$ items "Taken part in robbery" and "Stolen car to sell it" were removed to allow estimation of McDonald's $\omega$. 
Table A2.

Single-factor solution factor loadings and fit indices to assess unidimensionality for antisocial behaviour categories

\begin{tabular}{|c|c|c|c|c|c|c|}
\hline Category/Item & Factor loading & CFI & TLI & RMSEA & R-Squared $^{1}$ & $\begin{array}{c}\text { Proportion } \\
\text { Variance }^{2} \\
\end{array}$ \\
\hline Status / general delinquency / rule breaking & & .73 & .70 & .07 & .88 & .21 \\
\hline Disrupted people's games/work & 0.48 & & & & & \\
\hline Disrupted colleagues & 0.40 & & & & & \\
\hline Talked back impolitely & 0.38 & & & & & \\
\hline Sworn at others or called names & 0.45 & & & & & \\
\hline Not completed class or work tasks & 0.47 & & & & & \\
\hline Teased or made fun of someone else & 0.51 & & & & & \\
\hline Not paid proper fee & 0.48 & & & & & \\
\hline Been late for work & 0.40 & & & & & \\
\hline Missed a day of work without excuse & 0.42 & & & & & \\
\hline Done something against caregivers will & 0.58 & & & & & \\
\hline Tricked or pranked & 0.46 & & & & & \\
\hline Made abusive phone calls & 0.47 & & & & & \\
\hline Been warned by police but not arrested & 0.30 & & & & & \\
\hline Told a lie & 0.44 & & & & & \\
\hline Deliberately spread rumors & 0.51 & & & & & \\
\hline Lied to have a sickie & 0.55 & & & & & \\
\hline Carry a weapon & 0.25 & & & & & \\
\hline Gambling & 0.30 & & & & & \\
\hline Cheated on exam or assignment & 0.40 & & & & & \\
\hline Discrimination & 0.37 & & & & & \\
\hline Accept gifts and go with strangers & 0.29 & & & & & \\
\hline Run away from home & 0.29 & & & & & \\
\hline Stay out past curfew & 0.53 & & & & & \\
\hline Encourage others to break rules & 0.68 & & & & & \\
\hline Lied to caregivers whereabouts & 0.61 & & & & & \\
\hline Encouraged others to hurt someone & 0.51 & & & & & \\
\hline Aggression & & .65 & .58 & .15 & .87 & .29 \\
\hline Hit pushed punched or slapped someone & 0.50 & & & & & \\
\hline Deliberately hurt or beat up someone & 0.78 & & & & & \\
\hline Taken part in group fist fight & 0.76 & & & & & \\
\hline Used a weapon in a fight & 0.63 & & & & & \\
\hline Used forced to get money or property & 0.44 & & & & & \\
\hline Physical abuse toward partner & 0.23 & & & & & \\
\hline Beat someone up who did nothing to you & 0.46 & & & & & \\
\hline Thrown objects at people & 0.54 & & & & & \\
\hline Deliberately hurt animal & 0.48 & & & & & \\
\hline Deliberately hit caregivers & 0.33 & & & & & \\
\hline Deliberately hit siblings & 0.36 & & & & & \\
\hline Verbally or physically threaten someone & 0.62 & & & & & \\
\hline Physical force to dominate & 0.60 & & & & & \\
\hline Vehicle & & .86 & .81 & .08 & .73 & .22 \\
\hline Driven vehicle without license & 0.55 & & & & & \\
\hline
\end{tabular}




\begin{tabular}{|c|c|c|c|c|c|c|}
\hline Drunk driving & 0.50 & & & & & \\
\hline Taken vehicle without permission & 0.21 & & & & & \\
\hline Joyride in stolen car & 0.24 & & & & & \\
\hline Driven at high speeds & 0.40 & & & & & \\
\hline Raced other vehicles & 0.56 & & & & & \\
\hline Driven in unregistered vehicle & 0.49 & & & & & \\
\hline Ride in vehicle without seatbelt & 0.56 & & & & & \\
\hline Ride without helmet & 0.52 & & & & & \\
\hline Substance use & & .65 & .54 & .19 & .82 & .31 \\
\hline Sniffed substance on purpose & 0.29 & & & & & \\
\hline Drunk alcohol & 0.55 & & & & & \\
\hline Drunk alcohol in unlicensed place & 0.58 & & & & & \\
\hline Smoked cigarettes & 0.66 & & & & & \\
\hline Used cannabis & 0.71 & & & & & \\
\hline Used amphetamines & 0.62 & & & & & \\
\hline Used other hard drugs & 0.32 & & & & & \\
\hline Push or sold drugs & 0.48 & & & & & \\
\hline Binge drinking & 0.66 & & & & & \\
\hline Theft & & .66 & .52 & .19 & .79 & .29 \\
\hline Shoplifted & 0.55 & & & & & \\
\hline Stolen $\$ 50$ or more & 0.65 & & & & & \\
\hline Stolen less than $\$ 50$ & 0.59 & & & & & \\
\hline Cheated on machines & 0.30 & & & & & \\
\hline Bought used or sold something stolen & 0.43 & & & & & \\
\hline Stolen employer property & 0.42 & & & & & \\
\hline Stolen from bicycle & 0.66 & & & & & \\
\hline Stolen from car or motorbike & 0.63 & & & & & \\
\hline Property & & .86 & .79 & .14 & .83 & .38 \\
\hline Deliberate destruction of things that don't belong to you & 0.63 & & & & & \\
\hline Deliberately messed up other's property & 0.75 & & & & & \\
\hline Deliberately damaged public property & 0.78 & & & & & \\
\hline Deliberately damage work property & 0.54 & & & & & \\
\hline Graffiti in public spaces & 0.54 & & & & & \\
\hline Entered premises without permission & 0.50 & & & & & \\
\hline Deliberately damaged property in own home & 0.49 & & & & & \\
\hline Technology-related & & 1 & 1 & .00 & .70 & .30 \\
\hline Download copyrighted material & 0.26 & & & & & \\
\hline Cyber-bullying & 0.44 & & & & & \\
\hline Impersonate online & 0.78 & & & & & \\
\hline Hacked personal accounts & 0.59 & & & & & \\
\hline Sexual-related & & 68 & .05 & .26 & .65 & .26 \\
\hline Unprotected sex & 0.23 & & & & & \\
\hline Have sex for means & 0.71 & & & & & \\
\hline Force sex & 0.64 & & & & & \\
\hline Sexting & 0.25 & & & & & \\
\hline
\end{tabular}

$* p<.05$

CFI = Comparative Fit Index (incremental measure of fit); RMSEA = Root Mean Square Error of Approximation (absolute measure of residual fit); TLI = Tucker-Lewis Index (incremental measure of fit). 
Items with factor loadings $>.30$ in bold.

${ }_{1}$ Multiple R-squared factors and factor score estimates.

${ }^{2}$ Proportion of variance accounted for by a single factor solution. 

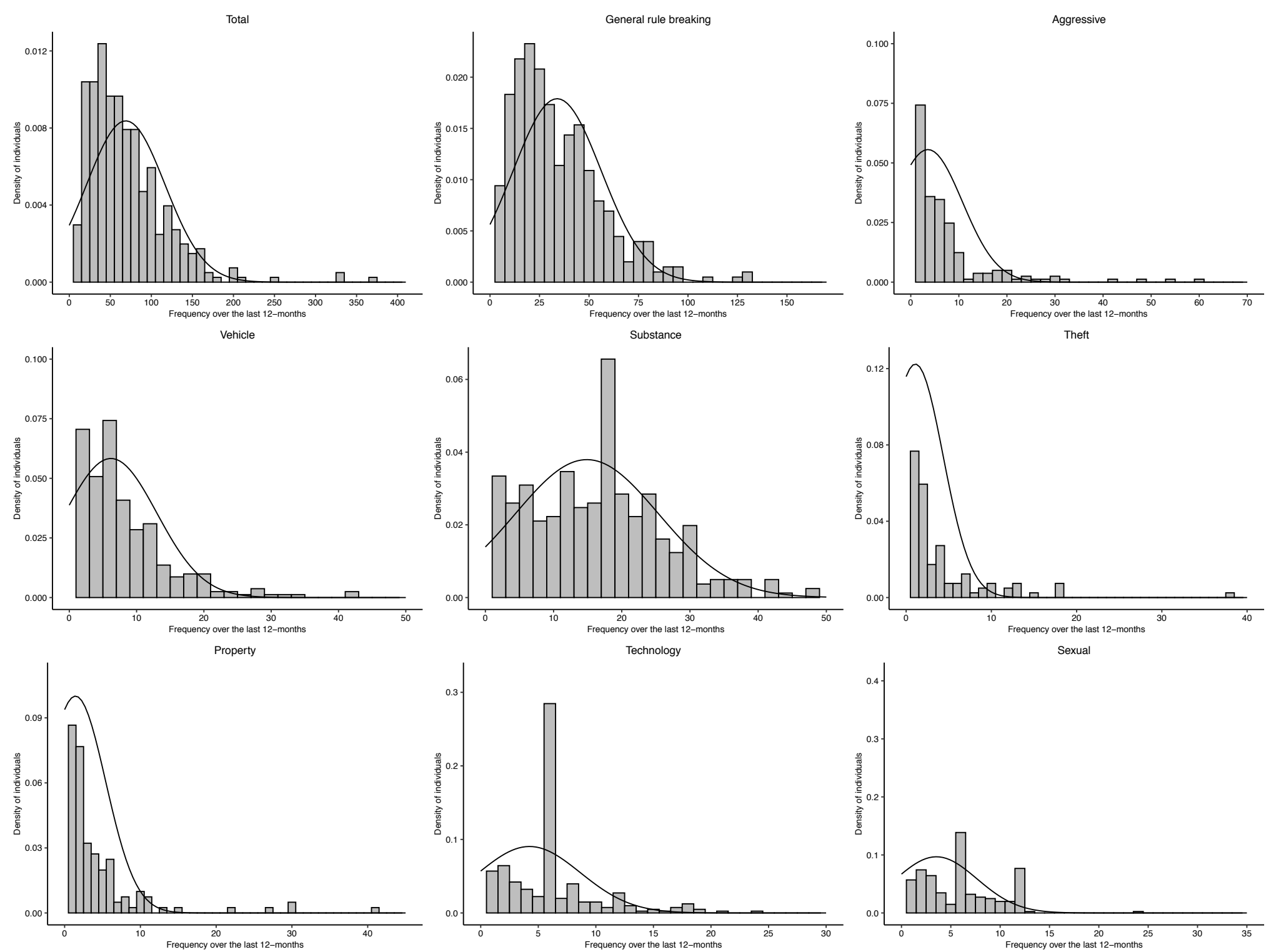

Figure 1. Density distributions of self-reported frequency of involvement in antisocial behaviour over the last 12 months. 

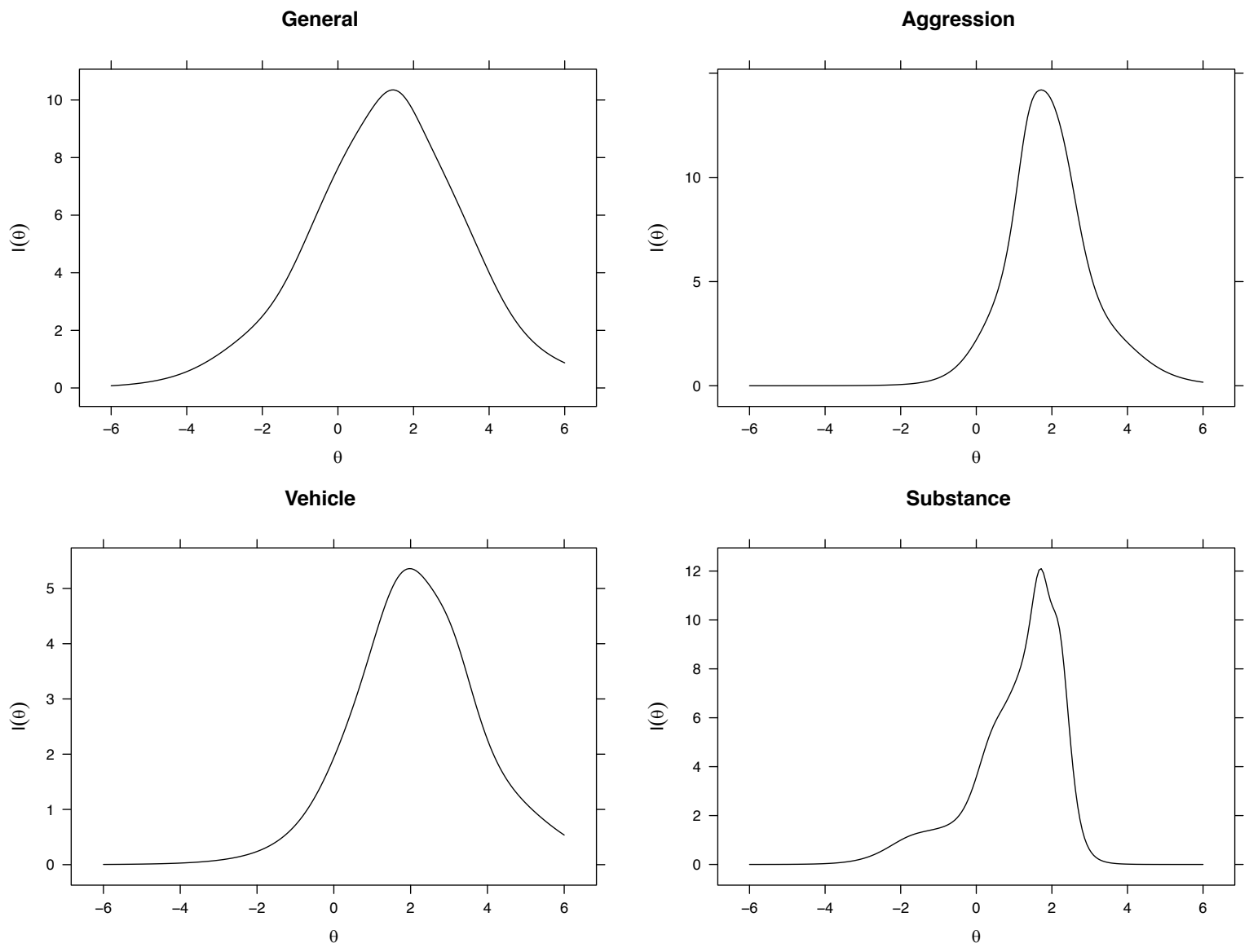

Theft
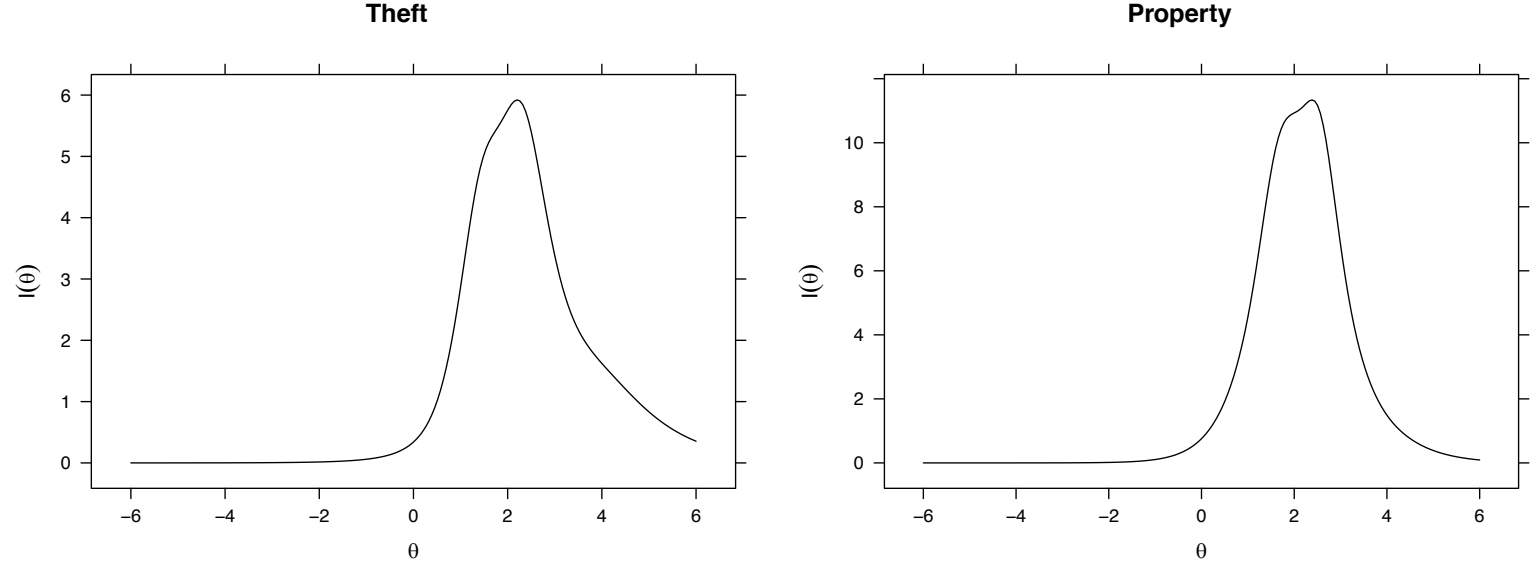

Technology
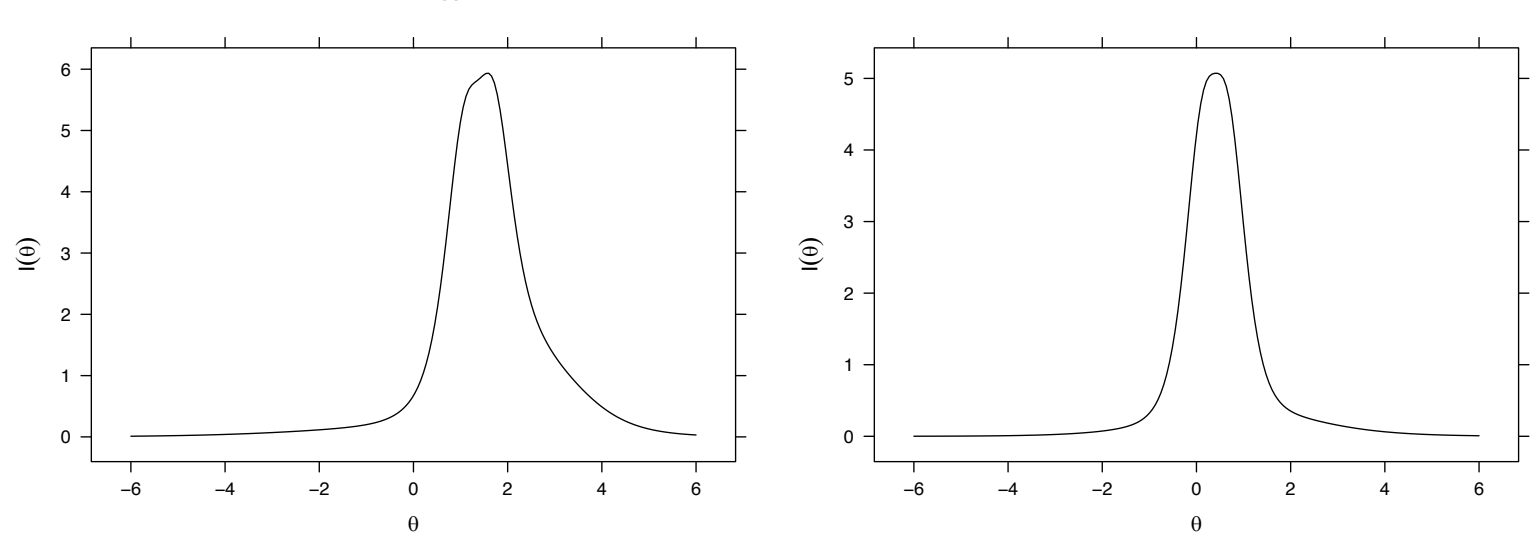

Figure 2. Total test information curves for each antisocial behaviour scale category. 

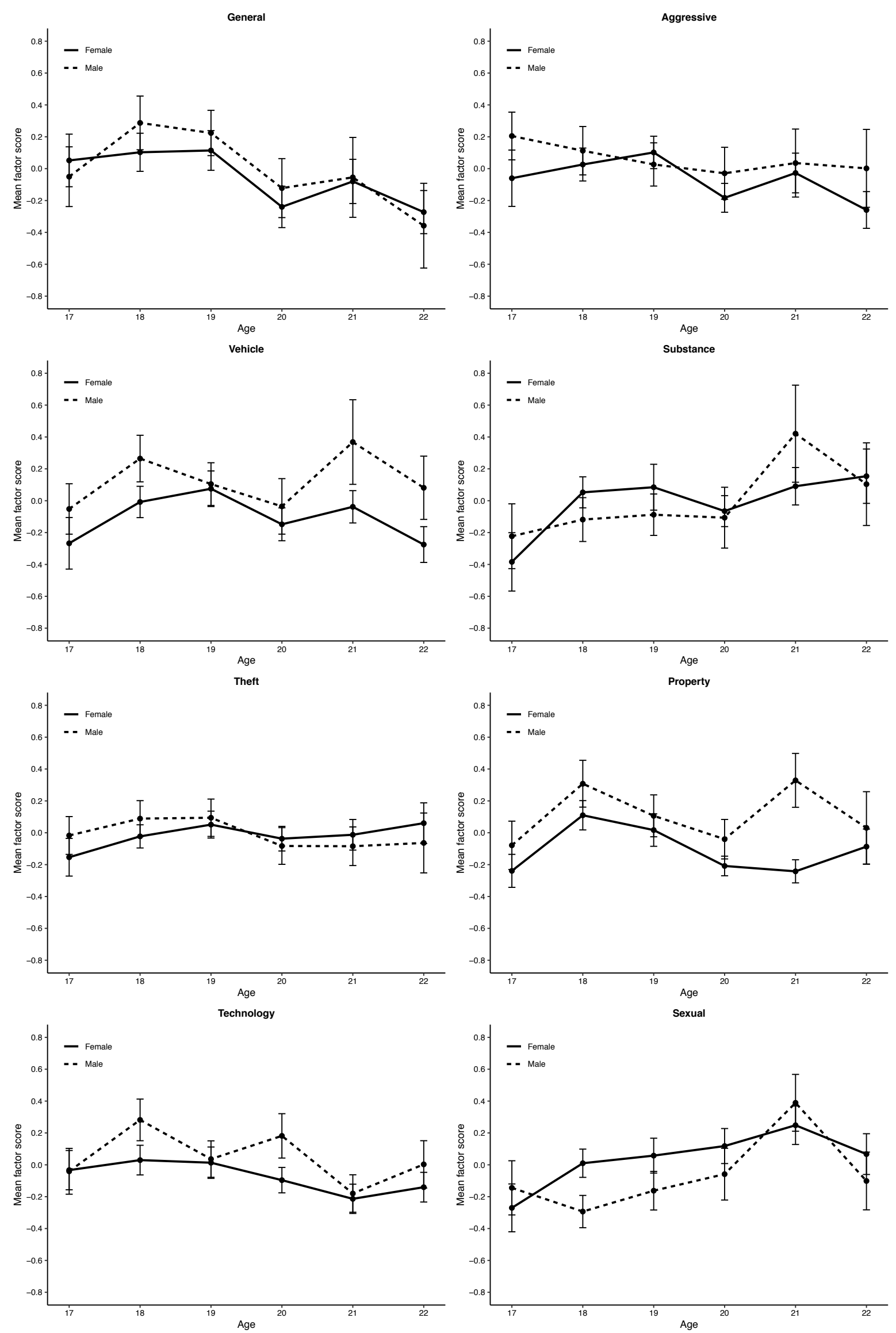

Figure 3. Mean composite factor score line plots across age and separated by sex for each antisocial behaviour category. 